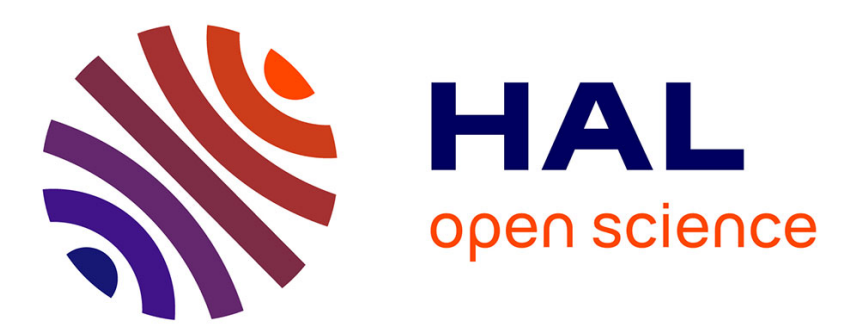

\title{
A C1 finite element for flexural and torsional analysis of rectangular piezoelectric laminated/sandwich composite beams
}

\author{
M. Ganapathi, Badri Patel, Maurice Touratier
}

\section{- To cite this version:}

M. Ganapathi, Badri Patel, Maurice Touratier. A C1 finite element for flexural and torsional analysis of rectangular piezoelectric laminated/sandwich composite beams. International Journal for Numerical Methods in Engineering, 2004, 61, pp.584-610. 10.1002/nme.1082 . hal-00019245

\section{HAL Id: hal-00019245 \\ https://hal.science/hal-00019245}

Submitted on 17 Apr 2018

HAL is a multi-disciplinary open access archive for the deposit and dissemination of scientific research documents, whether they are published or not. The documents may come from teaching and research institutions in France or abroad, or from public or private research centers.
L'archive ouverte pluridisciplinaire HAL, est destinée au dépôt et à la diffusion de documents scientifiques de niveau recherche, publiés ou non, émanant des établissements d'enseignement et de recherche français ou étrangers, des laboratoires publics ou privés. 


\title{
A $\mathrm{C}^{1}$ finite element for flexural and torsional analysis of rectangular piezoelectric laminated/sandwich composite beams
}

\author{
M. Ganapathi ${ }^{1}$, B. P. Patel ${ }^{1, *, \dagger}$ and M. Touratier ${ }^{2}$ \\ ${ }^{1}$ Institute of Armament Technology, Girinagar, Pune-411 025, India \\ ${ }^{2}$ LMSP, URA CNRS, ENSAM, 151, Bd de l'Hopital, 75013 Paris, France
}

This work deals with the development of a new $\mathrm{C}^{1}$ finite element for analysing the bending and torsional behaviour of rectangular piezoelectric laminated/sandwich composite beams. The formulation includes transverse shear, warping due to torsion, and elastic-electric coupling effects. It also accounts for the inter-layer continuity condition at the interfaces between layers, and the boundary conditions at the upper and lower surfaces of the beam. The shear strain is represented by a cosine function of a higher order in nature and thus avoiding shear correction factors. The warping function obtained from a three-dimensional elasticity solution is incorporated in the present model. An exact integration is employed in evaluating various energy terms due to the application of field consistency approach while interpolating the transverse shear and torsional strains. The variation of the electric potential through the thickness is taken care of in the formulation based on the observation of three-dimensional solution. The performance of the laminated piezoelectric element is tested comparing with analytical results as well as with the reference solutions evaluated using three-dimensional finite element procedure. A detailed study is conducted to highlight the influence of length-to-thickness ratio on the displacements, stresses and electric potential field of piezoelectric laminated beam structures subjected to flexural and torsional loadings.

KEY WORDS: piezoelectric; flexural; torsional; sandwich; finite element; warping

\section{INTRODUCTION}

There has been an increasing interest in recent years in the development of lightweight smart structures for many engineering applications. For the weight optimization, the structures made of composite materials having high stiffness-to- and strength-to-weight ratios, and sandwiches separating the stiff facings with a thick core of low density as load-bearing substrates are preferred in aerospace engineering. Such structures are integrated with distributed piezoelectric

\footnotetext{
*Correspondence to: B. P. Patel, Institute of Armament Technology, Girinagar, Pune-411 025, India.

†E-mail: badripatel@hotmail.com

Contract/grant sponsor: Indo French Centre for the Promotion of Advanced Research; contract/grant number: 2308-1
} 
materials that act as sensors and actuators because of the direct and converse piezoelectric effects, respectively. These structural members while integrated with suitable control strategies and circuits have the self-monitoring and self-controlling capabilities. For the effective utilization of such structures, there is a growing appreciation among researchers in accurately modelling and simulating the characteristics of smart composite structures.

Study on the behaviour of smart structures has received considerable attention in the literature and reviewed by Tang et al. [1], Saravanos and Heyliger [2], Sunar and Rao [3], and Benjeddou [4]. It is shown that the structures, in general, are characterized using classical/first-order shear deformation theory coupled with either neglecting the electro-elastic interactions or introducing constant electric field intensity over the piezoelectric layers with the substrate. It can be further concluded that most of the studies are devoted to the flexural analysis of laminated smart composite structures. Furthermore, a few studies have been devoted to the analysis of structures with higher-order/layer-wise theory, and also assuming the through thickness variation for the electric field of piezoelectric layers [5-10]. It is also observed that the available work of smart structures is largely pertaining to laminated plates. Attempts are also made in deriving the exact/analytical solutions for simple cases of geometry and boundary conditions [11-15]. As the exact solution is not possible/feasible for more general cases of loading and complicated boundary conditions, the improved approximate techniques such as finite element method has been explored for the simulation of the behaviour of smart structures [5, 8, 16-18]. However, in analysing thick smart structures, 3D finite elements $[19,20]$ are used which are computationally expensive. But it is highly desirable for the designers/analysts to have a model that can capture the important 3D effects due to the through-thickness variations of displacements and stresses in thick laminates but maintain the efficiency and convenience of a $1 \mathrm{D}$ model. To the best of authors' knowledge, however, the study on the torsion of laminated piezoelectric composite beam structures has not received adequate attention in the literature [21-25].

Here, a new finite element for the analysis of laminated smart beam with rectangular cross-section, having only the independent generalized displacements and electric potential, is proposed by extending the recent work of Ganapathi et al. [24]. The element developed is one-dimensional model from the point of view of structural behaviour and utilizes $\mathrm{C}^{1}$ continuous function for the transverse displacement associated with bending in accordance with the refined shear deformation theory, and the torsional warping of the beam is accounted for based on 3D elasticity solution. The electric field variation is taken as three-dimensional one in which quadratic form of through-thickness variation in the piezoelectric layer is considered. The element has good features for all the standard requirements such as free from locking, spurious rigid modes, etc. The formulation includes electro-elastic coupling effects, and has no requirement of introducing arbitrary shear correction factor as the shear strain is defined through the cosine function of a higher order nature. The efficacy of the present formulation is tested comparing the solutions with those of three-dimensional analysis. A detailed study is carried out to bring out the effect of length-to-thickness ratio on the variation of displacements, stresses and electric potential fields due to both bending and torsional loads.

\section{FORMULATION}

A laminated composite beam is considered with the co-ordinates $x$ along the length, $y$ along the width and $z$ along the thickness directions as shown in Figure 1. The displacements in 

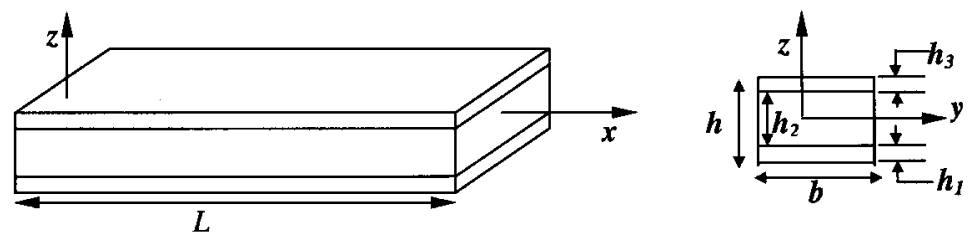

Figure 1. Laminated beam co-ordinate system.

$k$ th layer $u^{k}, v^{k}$ and $w^{k}$ at point $(x, y, z)$ from the median surface are expressed as functions of mid-plane displacements $u_{0}, v_{0}, w_{0}$, independent shear bending rotations $\theta_{x}$ and $\theta_{y}$ of the normal in $x z$ and $y z$ planes. They are also the functions of torsional rotation $\theta$ and independent parameter $\gamma$ for torsional rotation gradient in the length direction as

$$
\begin{aligned}
u^{k}(x, y, z)= & u_{0}(x)-y v_{0},,_{x}(x)+f_{2}(y)\left[v_{0},{ }_{x}(x)+\theta_{y}(x)\right]-z w_{0},{ }_{x}(x) \\
& +\left[f_{3}(z)+g^{k}(z)\right]\left[w_{0},,_{x}(x)+\theta_{x}(x)\right]+\psi^{k}(y, z) \gamma(x) \\
v^{k}(x, y, z)= & v_{0}(x)-z \theta(x) \\
w^{k}(x, y, z)= & w_{0}(x)+y \theta(x)
\end{aligned}
$$

where the subscript comma denotes the partial derivative with respect to spatial co-ordinate succeeding it. The functions $f_{2}(y), f_{3}(z)$ and $g^{k}(z)$ are defined as

$$
\begin{aligned}
& f_{2}(y)=b / \pi \sin (\pi y / b) \\
& f_{3}(z)=h / \pi \sin (\pi z / h)-h / \pi b_{55} \cos (\pi z / h) \\
& g^{k}(z)=a^{k} z+b^{k}
\end{aligned}
$$

$b$ and $h$ are width and total thickness of the beam.

In Equation (2), coefficients $b^{k}$ are determined such that the contribution to the displacement component $u^{k}$, due to bending in $x z$ plane, is continuous at the interface of adjacent layers and is zero at the mid-point of the cross-section. Finally, coefficients $b_{55}$ and $a^{k}$ in Equation (2) are computed from the requirement that the transverse shear stress due to bending in $x z$ plane is continuous at the interface of the adjacent layers and vanishes at the top and bottom surfaces of the beam. The detailed derivation of these constants $b_{55}, a^{k}$ and $b^{k}$ can be obtained from the work of Beakou and Touratier [26]. The kinematics shown in Equation (1), in particular for torsion, allows one to represent the constrained torsion where axial stress is not zero, for instance near the clamped support, and free torsion i.e. Saint-Venant torsion when $\gamma$ approaches $\theta, x$, which may be realized far away from the support of a thin beam.

The torsional warping function $\psi^{k}$ used in defining the kinematics in Equation (1) is the solution derived from three-dimensional elasticity equations in conjunction with Saint-Venant assumption of torsion, for composite beam of rectangular cross-section made of different layers. 
The general expression for $\psi^{k}$ is taken in the form of a harmonic function and is expressed as

$$
\psi^{k}=\sum_{N=1,3, \ldots}^{\infty}\left(C_{N}^{k} \sinh (\alpha z)+D_{N}^{k} \cosh (\alpha z)\right) \sin (\alpha y)+y z
$$

where $\alpha$ is defined as $N \pi / b$.

The coefficients $C_{N}^{k}$ and $D_{N}^{k}$, in Equation (3), while defining the warping function for the rectangular cross-section, are determined such that the contribution to the displacement component $u^{k}$ due to torsion is continuous at the interface of adjacent layers, and the transverse shear stress associated with torsion, is continuous at the interface of the adjacent layers and vanishes at the top and bottom surfaces of the beam [27].

The strains in terms of mid-plane deformation for $k$ th layer can be written as

$$
\left\{\varepsilon^{k}\right\}=\left\{\begin{array}{c}
\varepsilon_{p} \\
0 \\
0
\end{array}\right\}+\left\{\begin{array}{c}
\varepsilon_{x x}^{k} \\
2 \varepsilon_{x z}^{k} \\
2 \varepsilon_{x y}^{k}
\end{array}\right\}^{\mathrm{b}}+\left\{\begin{array}{c}
\varepsilon_{x x}^{k} \\
2 \varepsilon_{x z}^{k} \\
2 \varepsilon_{x y}^{k}
\end{array}\right\}^{\mathrm{t}}
$$

where superscripts $b$ and $t$ denote the strain contributions due to bending and torsion, respectively.

The mid-plane strains, $\varepsilon_{p}$, strain terms associated with bending and torsion in Equation (4) are written as

$$
\begin{aligned}
& \varepsilon_{p}=u_{0, x} \\
& \left\{\begin{array}{c}
\varepsilon_{x x}^{k} \\
2 \varepsilon_{x z}^{k} \\
2 \varepsilon_{x y}^{k}
\end{array}\right\}^{\mathrm{b}}=\left\{\begin{array}{c}
-z w_{0, x x}+\left[f_{3}(z)+g^{k}(z)\right]\left[w_{0, x x}+\theta_{x, x}\right]-y v_{0, x x}+f_{2}(y)\left(v_{0, x x}+\theta_{y, x}\right) \\
\left(f_{3, z}+g_{, z}^{k}\right)\left(w_{0, x}+\theta_{x}\right) \\
f_{2, y}\left(v_{0, x}+\theta_{y}\right)
\end{array}\right\} \\
& \left\{\begin{array}{c}
\varepsilon_{x x}^{k} \\
2 \varepsilon_{x z}^{k} \\
2 \varepsilon_{x y}^{k}
\end{array}\right\}=\left\{\begin{array}{c}
\psi^{k} \gamma_{, x} \\
\psi_{, z}^{k} \gamma+y \theta_{, x} \\
\psi_{, y}^{k} \gamma-z \theta_{, x}
\end{array}\right\}
\end{aligned}
$$

The total strain can be rewritten as

$$
\left\{\varepsilon^{k}\right\}=\left\{\begin{array}{c}
\varepsilon_{x x} \\
2 \varepsilon_{x z} \\
2 \varepsilon_{x y}
\end{array}\right\}=[Z]\{\bar{\varepsilon}\}
$$


where

$$
\begin{aligned}
& {[Z]=\left[\begin{array}{cccccccccc}
1 & y & f_{2} & z & f_{3}+g^{k} & 0 & 0 & 0 & 0 & \psi^{k} \\
0 & 0 & 0 & 0 & 0 & 0 & f_{3, z}+g_{, z}^{k} & y & \psi_{, z}^{k} & 0 \\
0 & 0 & 0 & 0 & 0 & f_{2, y} & 0 & -z & \psi_{, y}^{k} & 0
\end{array}\right]}
\end{aligned}
$$

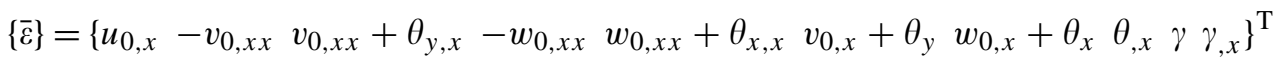

For a composite laminated beam of layer thickness $h_{k}(k=1,2,3 \ldots)$, and the ply-angle $\beta_{k}(k=1,2,3, \ldots)$, the necessary expressions for computing the stiffness coefficients, available in the literature [28], are used.

The stress-strain relation, incorporating the piezoelectric effect, for $k$ th layer is written as

$$
\begin{aligned}
\left\{\sigma^{k}\right\} & =\left[\begin{array}{ccc}
Q_{11}^{k} & 0 & Q_{16}^{k} \\
0 & Q_{44}^{k} & 0 \\
Q_{16}^{k} & 0 & Q_{66}^{k}
\end{array}\right]\left\{\varepsilon^{k}\right\}-\left[\begin{array}{ccc}
0 & 0 & \bar{e}_{31}^{k} \\
\bar{e}_{14}^{k} & \bar{e}_{24}^{k} & 0 \\
0 & 0 & \bar{e}_{36}^{k}
\end{array}\right]\left\{\begin{array}{c}
E_{x}^{k} \\
E_{y}^{k} \\
E_{z}^{k}
\end{array}\right\} \\
\left\{\begin{array}{c}
D_{x}^{k} \\
D_{y}^{k} \\
D_{z}^{k}
\end{array}\right\} & {\left[\begin{array}{ccc}
0 & \bar{e}_{14}^{k} & 0 \\
0 & \bar{e}_{24}^{k} & 0 \\
\bar{e}_{31}^{k} & 0 & \bar{e}_{36}^{k}
\end{array}\right]\left\{\varepsilon^{k}\right\}+\left[\begin{array}{ccc}
\bar{\kappa}_{11}^{k} & \bar{\kappa}_{12}^{k} & 0 \\
\bar{\kappa}_{21}^{k} & \bar{\kappa}_{22}^{k} & 0 \\
0 & 0 & \bar{\kappa}_{33}^{k}
\end{array}\right]\left\{\begin{array}{c}
E_{x}^{k} \\
E_{y}^{k} \\
E_{z}^{k}
\end{array}\right\} }
\end{aligned}
$$

where $Q_{i j}^{k}(i, j=1,4,6)$ are the reduced stiffness coefficients of $k$ th layer, $\bar{e}_{i j}^{k}$ are reduced piezoelectric coefficients, $\bar{\kappa}_{i j}^{k}$ are reduced dielectric coefficients, $D_{x}^{k}, D_{y}^{z}$ and $D_{z}^{k}$ are electrical displacements.

The electrical field intensities $E_{x}^{k}, E_{y}^{k}$ and $E_{z}^{k}$ can be related to the electric potential $\phi^{k}$ as

$$
\left\{\begin{array}{lll}
E_{x}^{k} & E_{y}^{k} & E_{z}^{k}
\end{array}\right\}^{\mathrm{T}}=-\left\{\frac{\partial \phi^{k}}{\partial x} \frac{\partial \phi^{k}}{\partial y} \frac{\partial \phi^{k}}{\partial z}\right\}^{\mathrm{T}}
$$

The total potential energy functional $U$ of the system is given as

$$
\begin{aligned}
U(\delta)= & (1 / 2) \int_{0}^{L} \int_{-b / 2}^{b / 2} \sum_{k} \int_{h_{k}}^{h_{k+1}}\left[\left\{\sigma^{k}\right\}^{\mathrm{T}}\left\{\varepsilon^{k}\right\}-\left\{D^{k}\right\}^{\mathrm{T}}\left\{E^{k}\right\}\right] \mathrm{d} x \mathrm{~d} y \mathrm{~d} z \\
& -\int_{0}^{L}\{d\}^{\mathrm{T}}\left\{\begin{array}{llllll}
f_{x} & f_{y} & f_{z} & m_{y} & m_{z} & m_{x}
\end{array}\right\}^{\mathrm{T}} \mathrm{d} x
\end{aligned}
$$


where $\delta$ and $L$ are the vector of the generalized co-ordinates and length of the beam, respectively. $f_{x}, f_{y}, f_{z}$ are the distributed forces in $x, y$ and $z$ directions and $m_{x}, m_{y}, m_{z}$ are the distributed moments about $x, y$ and $z$ axes. The vector $\{d\}$ is the vector of generalized displacements and is given by $\{d\}^{\mathrm{T}}=\left\{\begin{array}{llllll}u_{0} & v_{0} & w_{0} & \theta_{x} & \theta_{y} & \theta\end{array}\right\}$.

Using Equations (6) and (7), Equation (9) can be rewritten as

$$
\begin{aligned}
U(\delta)= & 1 / 2 \int_{0}^{L} \int_{-b / 2}^{b / 2} \sum_{k} \int_{h_{k}}^{h_{k+1}}\left[\{\bar{\varepsilon}\}^{\mathrm{T}}[Z]^{\mathrm{T}}\left[Q^{k}\right][Z]\{\bar{\varepsilon}\}-\left\{E^{k}\right\}^{\mathrm{T}}[e][Z]\{\bar{\varepsilon}\}\right. \\
& \left.-\{\bar{\varepsilon}\}^{\mathrm{T}}[Z]^{\mathrm{T}}[e]\left\{E^{k}\right\}-\left\{E^{k}\right\}^{\mathrm{T}}[\kappa]\left\{E^{k}\right\}\right] \mathrm{d} x \mathrm{~d} y \mathrm{~d} z \\
& -\int_{0}^{L}\{d\}^{\mathrm{T}}\left\{\begin{array}{llllll}
f_{x} & f_{y} & f_{z} & m_{y} & m_{z} & m_{x}
\end{array}\right\}^{\mathrm{T}} \mathrm{d} x
\end{aligned}
$$

The governing equations obtained by minimization of total potential energy functional given by Equation (10) can be analytically/numerically solved.

Here, finite element approach, developing an element describing the structural field variables through three nodes along the length and the electrical field variable three-dimensionally through 27 nodes, is employed. The structural fields are based on Hermite cubic functions for transverse displacements ( $v_{0}$ and $w_{0}$ according to the $\mathrm{C}^{1}$ continuity requirements), quadratic functions for rotations $\left(\theta_{x}, \theta_{y}\right.$ and $\left.\theta\right)$, and linear functions for in-plane displacement, $u_{0}$ and rotation gradient pertaining to torsion, $\gamma$. The electric potential $\phi^{k}$ is interpolated using Lagrangian function with quadratic variation along length $(x)$, width $(y)$ and thickness $(z)$ directions. Accordingly, the element needs nine structural $\left(u_{0}, v_{0}, v_{0},{ }_{x}, w_{0}, w_{0},{ }_{x}, \theta_{x}, \theta_{y}, \theta\right.$ and $\left.\gamma\right)$ degrees of freedom at both ends of the 3 -noded beam element and the centre node requires three structural degrees of freedom $\theta_{x}, \theta_{y}$, and $\theta$, as shown in Figure 2(a). Similarly, the description of electrical potential field is based on one degree of freedom per node in all the 27 nodes of the element, i.e. 3 nodes in all directions as shown in Figure 2(b). To account for the accurate variation of electrical field, each layer can be divided into many such elements through thickness, along the length and width directions of beam structure. The actual element for the analysis is the integration of Figures 2(a) and (b).

For obtaining the element level governing equations, the vectors $\{\bar{\varepsilon}\}$ and $\{d\}$ involved in Equation (10) are expressed in terms of shape/interpolation functions, their derivatives and the vector of element level degrees of freedom/generalized displacements $\left\{\delta_{u}^{e}\right\}$ as

$$
\{\bar{\varepsilon}\}_{10 \times 1}=\left[B_{u}\right]_{10 \times 21}\left\{\delta_{u}^{e}\right\}_{21 \times 1} ; \quad\{d\}_{6 \times 1}=\left[H_{u}\right]_{6 \times 21}\left\{\delta_{u}^{e}\right\}_{21 \times 1}
$$

The matrices $\left[B_{u}\right],\left[H_{u}\right]$ and vector $\left\{\delta_{u}^{e}\right\}$ involved in Equation (1) are defined in Appendix A.

Similarly, the electric field intensity vector in an element within the layer can be expressed in terms of Lagrangian shape functions, their derivatives and element level potential degrees of freedom as

$$
\left\{E^{k}\right\}_{3 \times 1}=-\left[\bar{Z}_{\phi}\right]_{3 \times 18}\left[B_{\phi}\right]_{18 \times 27}\left\{\delta_{\phi}^{e}\right\}_{27 \times 1}
$$

The matrices $\left[\bar{Z}_{\phi}\right],\left[B_{\phi}\right]$ and vector $\left\{\delta_{\phi}^{e}\right\}$ involved in Equation (12) are given in Appendix B. 


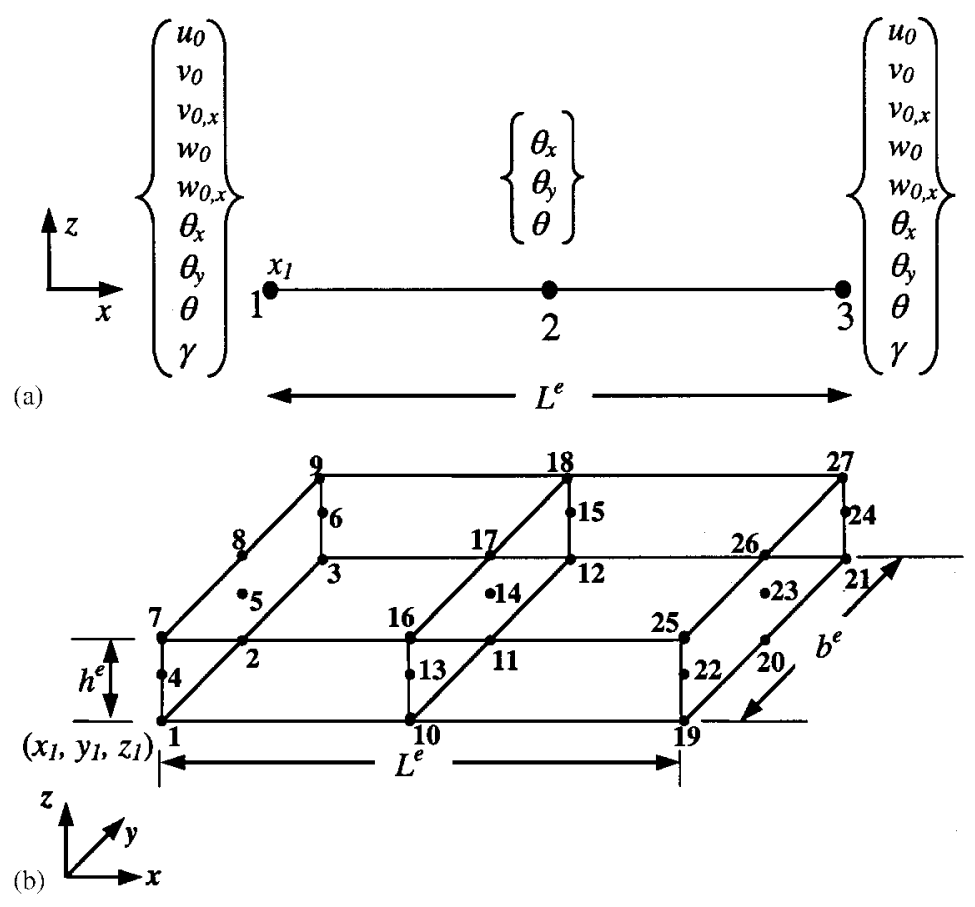

Figure 2. (a) Details of structural degrees of freedom of piezoelectric beam element; and (b) description of electrical potential degrees of freedom (1 DOF per node) in piezoelectric beam element.

Using Equations (11) and (12), the total potential energy expression for the element can be written as

$$
U\left(\delta_{u}^{e}, \delta_{\phi}^{e}\right)=\frac{1}{2}\left\{\begin{array}{c}
\delta_{u}^{e} \\
\delta_{\phi}^{e}
\end{array}\right\}^{\mathrm{T}}\left[\begin{array}{cc}
{\left[K_{u u}^{e}\right]} & {\left[K_{u \phi}^{e}\right]} \\
{\left[K_{\phi u}^{e}\right]} & {\left[K_{\phi \phi}^{e}\right]}
\end{array}\right]\left\{\begin{array}{c}
\delta_{u}^{e} \\
\delta_{\phi}^{e}
\end{array}\right\}-\left\{\delta_{u}^{e}\right\}^{\mathrm{T}}\left\{F_{u}^{e}\right\}
$$

where $\left[K_{u u}^{e}\right],\left[K_{\phi \phi}^{e}\right],\left[K_{u \phi}^{e}\right]$ and $\left[K_{\phi u}^{e}\right]$ are the elemental stiffness matrices resulting from mechanical, electrical fields and due to electro-mechanical couplings, and $\left\{F_{u}^{e}\right\}$ the elemental load vector due to applied mechanical loads.

The minimization of total potential energy functional given by Equation (13) leads to the governing equation for the element as

$$
\left[\begin{array}{cc}
{\left[K_{u u}^{e}\right]} & {\left[K_{u \phi}^{e}\right]} \\
{\left[K_{\phi u}^{e}\right]} & {\left[K_{\phi \phi}^{e}\right]}
\end{array}\right]\left\{\begin{array}{c}
\left\{\delta_{u}^{e}\right\} \\
\left\{\delta_{\phi}^{e}\right\}
\end{array}\right\}=\left\{\begin{array}{c}
\left\{F_{u}^{e}\right\} \\
\{0\}
\end{array}\right\}
$$

The coefficients of stiffness matrices involved in governing equation (14) can be rewritten as the product of terms having thickness $(z)$ and width $(y)$ co-ordinate, and the term containing $x$. In the present study, while performing the integration, terms having thickness and width co-ordinates are explicitly integrated whereas the terms with $x$ are evaluated based on full integration, using 3 points Gauss integration rule. 
Following the finite element assembly procedure, the governing equations for the beam structure are obtained as

$$
\left[\begin{array}{cc}
{\left[K_{u u}^{\mathrm{G}}\right]} & {\left[K_{u \phi}^{\mathrm{G}}\right]} \\
{\left[K_{\phi u}^{\mathrm{G}}\right]} & {\left[K_{\phi \phi}^{\mathrm{G}}\right]}
\end{array}\right]\left\{\begin{array}{c}
\left\{\delta_{u}^{\mathrm{G}}\right\} \\
\left\{\delta_{\phi}^{\mathrm{G}}\right\}
\end{array}\right\}=\left\{\begin{array}{c}
\left\{F_{u}^{\mathrm{G}}\right\} \\
\{0\}
\end{array}\right\}
$$

where superscript $G$ denotes the global matrices and vector.

The Equation (15) can be solved using any standard method.

\section{RESULTS AND DISCUSSION}

The aim of the present study is to examine the efficacy of this new element for analysing the bending and torsional behaviours of the laminated or sandwich piezoelectric beam. The choice of the interpolation functions made here in developing the element allows to have the same order of interpolation for both $w_{0}, x_{x}$ and $\theta_{x}, v_{0}, x$ and $\theta_{y}$ in the definition of shear strain and permits to avoid transverse shear locking phenomena. Similarly, the $\theta,{ }_{x}$ and $\gamma$ in the torsional strain are interpolated with same degree polynomial which recovers the Saint-Venant torsion $(\gamma=\theta, x)$. The element behaves very well for both thick and thin situations as highlighted in the work of Ganapathi et al. [24]. Furthermore, it has been demonstrated [24] that this element has no spurious mode and is represented by correct rigid body modes pertaining to flexure and torsion when exact integration is applied to evaluate all the strain energy terms and, for the sake of brevity, these results are not presented here.

The problems chosen for the evaluation of the performance of the element are given below as:

\subsection{Flexural analysis}

Problem 1 (Simply supported laminated piezoelectric composite beam subjected to mechanical/ electrical loads (Reference [15])): The properties such as elastic, piezoelectric/dielectric coefficients used are

- for skin (PZT): $C_{11}=C_{22}=139 \mathrm{GPa}, C_{12}=77.8 \mathrm{GPa}, C_{13}=C_{23}=74.3 \mathrm{GPa}$, $C_{33}=115 \mathrm{GPa}, C_{44}=C_{55}=25.6 \mathrm{GPa}, C_{66}=30.6 \mathrm{GPa} ; e_{31}=-5.2 \mathrm{C} / \mathrm{m}^{2}, e_{32}=$ $-5.2 \mathrm{C} / \mathrm{m}^{2}, e_{33}=15.1 \mathrm{C} / \mathrm{m}^{2}, e_{15}=e_{24}=12.7 \mathrm{C} / \mathrm{m}^{2} ; \kappa_{11}=\kappa_{22}=13.06 \times 10^{-9} \mathrm{~F} / \mathrm{m}$, $\kappa_{33}=11.51 \times 10^{-9} \mathrm{~F} / \mathrm{m}$.

- for core (Graphite epoxy): $C_{11}=134.86 \mathrm{GPa}, C_{12}=C_{13}=5.1563 \mathrm{GPa}, C_{22}=C_{33}=$ $14.352 \mathrm{GPa}, C_{23}=7.1329 \mathrm{GPa}, C_{44}=3.60955 \mathrm{GPa}, C_{55}=C_{66}=5.654 \mathrm{GPa} ; \kappa_{11}=$ $\kappa_{22}=0.031 \times 10^{-9} \mathrm{~F} / \mathrm{m}, \kappa_{33}=0.0266 \times 10^{-9} \mathrm{~F} / \mathrm{m}$.

- Geometrical properties: Skin thickness $h_{1}=h_{3}=0.2 \mathrm{~h}$, core thickness $h_{2}=0.8 \mathrm{~h}$; width $b=0.0125 \mathrm{~m} ; L / h$ is varied as 10 and 50 .

Problem 2 (Cantilever piezoelectric sandwich beam subjected to mechanical/electrical loads): The material properties such as elastic, piezoelectric/dielectric coefficients are taken as

- $f o r$ face/skin (PZT): $E_{1}=66.0688 \mathrm{GPa}, E_{2}=66.0688 \mathrm{GPa}, E_{3}=54.6788 \mathrm{GPa}, G_{12}=$ $25 \mathrm{GPa}, G_{23}=29.5 \mathrm{GPa}, G_{13}=29.5 \mathrm{GPa}, v_{12}=0.324, v_{23}=0.4715, v_{13}=0.4715$; 
$e_{31}=-4.3 \mathrm{C} / \mathrm{m}^{2}, e_{32}=-4.3 \mathrm{C} / \mathrm{m}^{2}, e_{33}=16.7 \mathrm{C} / \mathrm{m}^{2}, e_{15}=11.8 \mathrm{C} / \mathrm{m}^{2}, e_{24}=11.8 \mathrm{C} / \mathrm{m}^{2}$; $\kappa_{11}=12.75 \times 10^{-9} \mathrm{~F} / \mathrm{m}, \kappa_{22}=12.75 \times 10^{-9} \mathrm{~F} / \mathrm{m}, \kappa_{33}=7.41 \times 10^{-9} \mathrm{~F} / \mathrm{m}$.

- for core: $E=70 \mathrm{GPa}, G=26.9 \mathrm{GPa}, v=0.3011, \rho=2700 \mathrm{~kg} / \mathrm{m}^{3}$.

- Geometrical parameters: Width $(b)=0.02 \mathrm{~m}$, total thickness of the beam $h=0.1 \mathrm{~m}$. The ratio of thickness of face-to-core $\left(h_{1} / h_{2}\right)$ is assumed as 2 and length to thickness ratio $(L / h)$ is varied as 3 and 10.
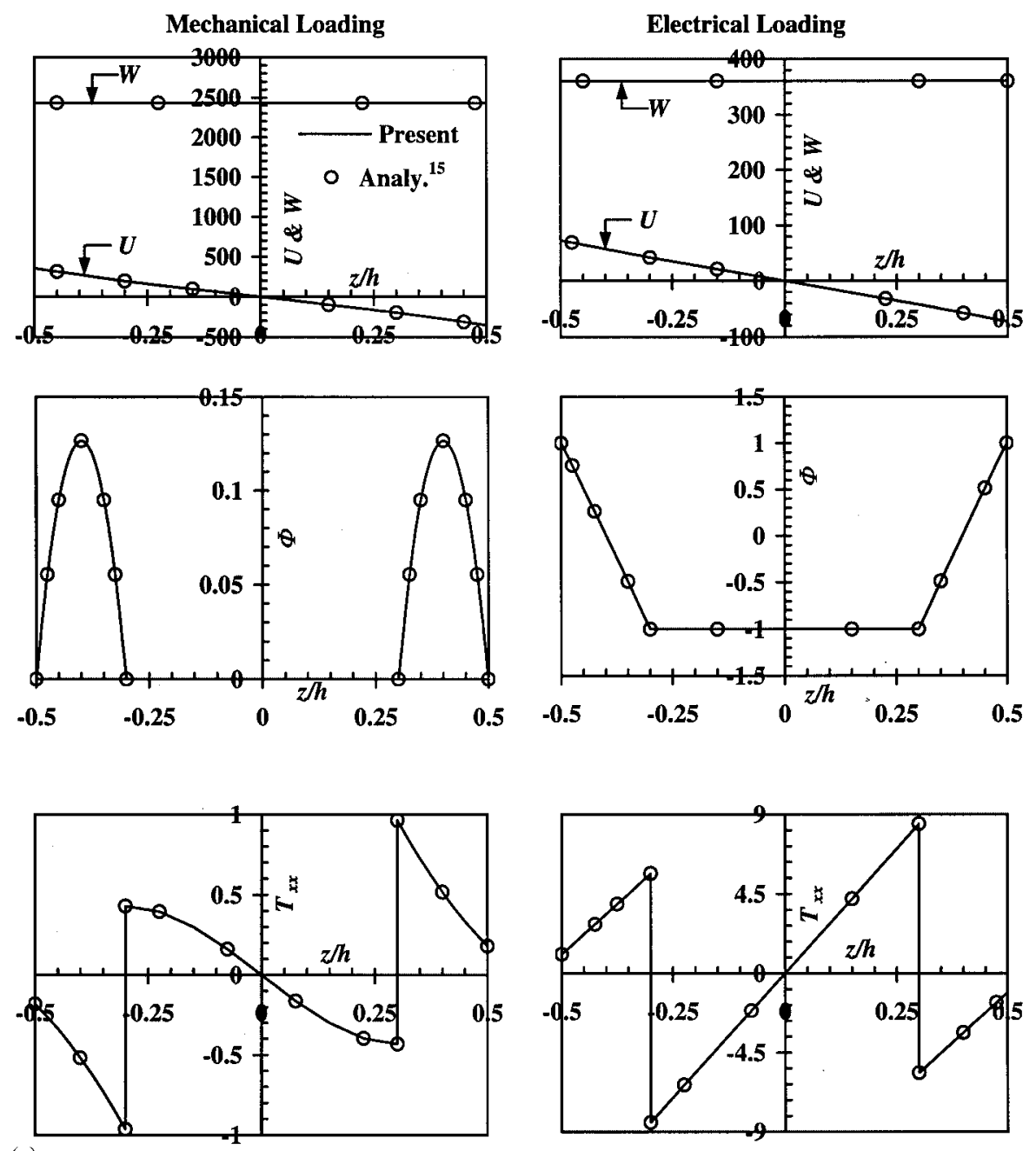

(a)

Figure 3. Comparison of non-dimensional displacements $(U$ and $W$ ), electrical potential

$(\Phi)$ and stress $T_{x x}$ for laminated piezoelectric beam subjected to mechanical (left side) and electrical (right side) loadings (in Problem No. 1): (a) $L / h=10$; and (b) $L / h=50$. 

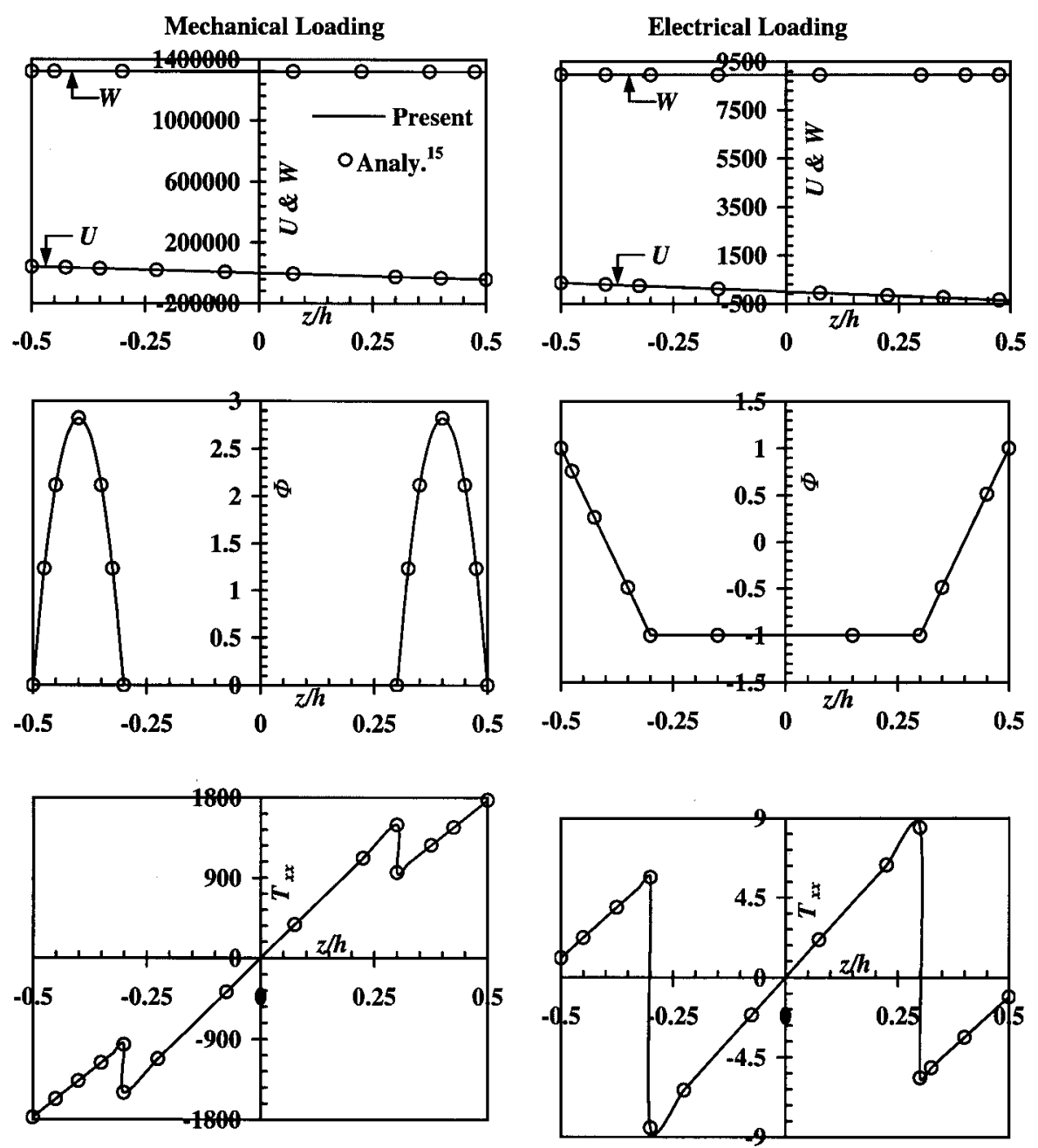

(b)

Figure 3. Continued.

\subsection{Torsional analysis}

Problem 3 (Cantilever piezoelectric (PZT/epoxy) sandwich beam subjected to mechanical/ electrical loads): The properties such as elastic, piezoelectric/dielectric coefficients considered here are (Reference [29]):

- for face (PZT/Epoxy): $E_{1}=37.8 \mathrm{GPa}, E_{2}=6.98 \mathrm{GPa}, E_{3}=6.98 \mathrm{GPa}, G_{12}=G_{23}=$ $G_{13}=2.89 \mathrm{GPa}, v_{12}=v_{23}=v_{13}=0.26 ; d_{31}=-274 \times 10^{-12} \mathrm{~m} / \mathrm{V}, d_{32}=-120 \times$ $10^{-12} \mathrm{~m} / \mathrm{V}, d_{33}=374 \times 10^{-12} \mathrm{~m} / \mathrm{V} ; \kappa_{11}=\kappa_{22}=\kappa_{33}=16.5 \times 10^{-9} \mathrm{~F} / \mathrm{m}$.

- for core: $E=73 \mathrm{GPa}, G=29.2 \mathrm{GPa}, v=0.25$. 
Table I. Convergence for No. of elements along thickness in each skin layer (Nesk) for Problem No. 2 (No. of elements along the width direction=1, No. of elements along the length=12).

\begin{tabular}{lcccccc}
\hline Nesk & $u(\mathrm{~m})$ & $w(\mathrm{~m})$ & $\phi(\mathrm{V})$ & $\sigma_{x x}\left(\mathrm{~N} / \mathrm{m}^{2}\right)$ & $\tau_{x z}\left(\mathrm{~N} / \mathrm{m}^{2}\right)$ & $\tau_{x z}^{*}\left(\mathrm{~N} / \mathrm{m}^{2}\right)$ \\
\hline 1 & $2.021 \mathrm{E}-07$ & $2.715 \mathrm{E}-06$ & 4.956 & 24200 & 742.6 & 567.4 \\
2 & $2.021 \mathrm{E}-07$ & $2.715 \mathrm{E}-06$ & 4.956 & 24200 & 742.6 & 567.4 \\
4 & $2.021 \mathrm{E}-07$ & $2.715 \mathrm{E}-06$ & 4.956 & 24200 & 742.6 & 567.4 \\
6 & $2.021 \mathrm{E}-07$ & $2.715 \mathrm{E}-06$ & 4.956 & 24200 & 742.6 & 567.4 \\
\hline
\end{tabular}

$(x, y, z)$ location for $u=(1.0 \mathrm{~m}, 0.0,-0.05 \mathrm{~m}),(x, y, z)$ location for $w=(1.0 \mathrm{~m}, 0.0,0.0),(x, y, z)$ location for $\phi$ and $\sigma_{x x}=(0.2 \mathrm{~m}, 0.0,-0.05 \mathrm{~m}),(x, y, z)$ location for $\tau_{x z}=(0.2 \mathrm{~m}, 0.0,0.0),(x, y, z)$ location for $\tau_{x z}^{*}=(0.2 \mathrm{~m}, 0.0,-0.025 \mathrm{~m})$.

Table II. Convergence for No. of elements along length (Nel) for problem No. 2 (No. of elements along the thickness in each skin layer $($ Nesk $)=4$, No. of elements along width $=1$ ).

\begin{tabular}{rcccccc}
\hline $\mathrm{Nel}$ & $u(\mathrm{~m})$ & $w(\mathrm{~m})$ & $\phi(\mathrm{V})$ & $\sigma_{x x}\left(\mathrm{~N} / \mathrm{m}^{2}\right)$ & $\tau_{x z}\left(\mathrm{~N} / \mathrm{m}^{2}\right)$ & $\tau_{x z}^{*}\left(\mathrm{~N} / \mathrm{m}^{2}\right)$ \\
\hline 2 & $2.021 \mathrm{E}-07$ & $2.714 \mathrm{E}-06$ & 4.951 & 24240 & 741.4 & 567.2 \\
4 & $2.021 \mathrm{E}-07$ & $2.714 \mathrm{E}-06$ & 4.962 & 24140 & 737.8 & 571.1 \\
6 & $2.021 \mathrm{E}-07$ & $2.715 \mathrm{E}-06$ & 4.955 & 24230 & 741 & 568 \\
8 & $2.021 \mathrm{E}-07$ & $2.715 \mathrm{E}-06$ & 4.955 & 24210 & 738.9 & 568.3 \\
10 & $2.021 \mathrm{E}-07$ & $2.715 \mathrm{E}-06$ & 4.956 & 24160 & 736.7 & 568.7 \\
12 & $2.021 \mathrm{E}-07$ & $2.715 \mathrm{E}-06$ & 4.956 & 24200 & 742.6 & 567.4 \\
14 & $2.021 \mathrm{E}-07$ & $2.715 \mathrm{E}-06$ & 4.956 & 24200 & 743 & 568 \\
16 & $2.021 \mathrm{E}-07$ & $2.715 \mathrm{E}-06$ & 4.956 & 24200 & 743.5 & 567 \\
18 & $2.021 \mathrm{E}-07$ & $2.715 \mathrm{E}-06$ & 4.956 & 24200 & 743.7 & 567.2 \\
20 & $2.021 \mathrm{E}-07$ & $2.715 \mathrm{E}-06$ & 4.956 & 24200 & 744 & 567.5 \\
\hline
\end{tabular}

$(x, y, z)$ location for $u=(1.0 \mathrm{~m}, 0.0,-0.05 \mathrm{~m}),(x, y, z)$ location for $w=(1.0 \mathrm{~m}, 0.0,0.0),(x, y, z)$ location for $\phi$ and $\sigma_{x x}=(0.2 \mathrm{~m}, 0.0,-0.05 \mathrm{~m}),(x, y, z)$ location for $\tau_{x z}=(0.2 \mathrm{~m}, 0.0,0.0),(x, y, z)$ location for $\tau_{x z}^{*}=(0.2 \mathrm{~m}, 0.0,-0.025 \mathrm{~m})$.

- Geometrical parameters: Width $(b)=0.15 \mathrm{~m}$, total thickness of the beam $h=0.1 \mathrm{~m}$, $h_{1}=0.025 \mathrm{~m}, h_{2}=0.05 \mathrm{~m}, h_{3}=0.025 \mathrm{~m}$, length $L=1 \mathrm{~m}$.

The boundary conditions used are

Simply supported case: $u_{0}=v_{0}=w_{0}=0$ at $x=0, L$.

Clamped end: $u_{0}=v_{0}=v_{0},{ }_{x}=w_{0}=w_{0},{ }_{x}=\theta_{x}=\theta_{y}=\theta=\gamma=0$ at $x=0$.

The transverse shear stress $\tau_{x z}$ is evaluated employing the constitutive relations and the $3 \mathrm{D}$ stress equations of equilibrium. Since the results yielded by the later method were found to be more close to three-dimensional finite element solutions, equilibrium equations are used for evaluating the transverse shear stress for the detailed study presented here.

Based on progressive mesh refinement, mesh idealization of 10-element along the length and 1-element in each piezoelectric layer along width and thickness directions is found to be adequate to model Problem 1, for the bending analysis. Further, for the flexural problems considered here, the solution is insensitive to number of terms in Equation (3) due to the absence of torsional warping. For mechanical case, a uniform pressure of $0.05 \mathrm{MPa}$ is assumed on top surface, in addition to zero electrical potential conditions at the top and bottom surfaces 

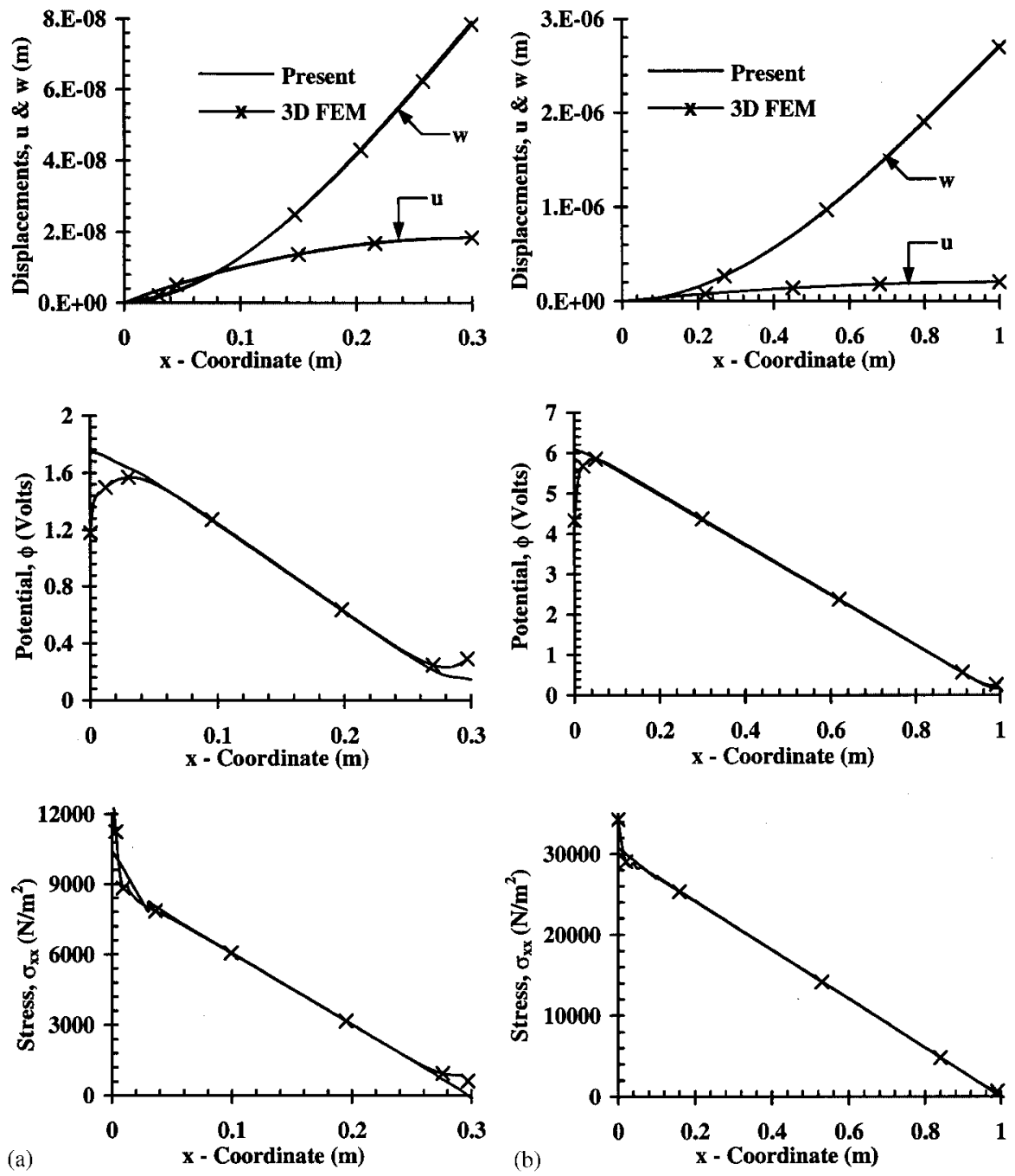

Figure 4. Distribution of displacements, electrical potential and stress along length (at $z=-0.05$ ) due to $1 \mathrm{~N}$ transverse tip load in Problem No. 2: (a) length to thickness ratio $(L / h)=3$ (left side); and (b) $L / h=10$ (right side).

as well as core of the beam. For electrical loading situation, the potential of $100 \mathrm{~V}$ at the top and bottom surfaces of the beam, and $-100 \mathrm{~V}$ at the top and bottom surfaces of the core are applied. The normalized displacements/stress due to mechanical load $\left(U=u(0,0, z) C_{00} /(h q)\right.$; $W=w(L / 2,0, z) C_{00} /(h q) ; \Phi=\phi(L / 2,0, z) C_{00} /\left(h q E_{0}\right) ; T_{11}=\sigma_{11}(L / 2,0, z) / q$ where $C_{00}=134.86 \mathrm{GPa}$ and $\left.E_{0}=1 \times 10^{10} \mathrm{~V} / \mathrm{m}\right)$ and applied electrical field $\left(U=u(0,0, z) E_{0} / V_{0}\right.$; $W=w(L / 2,0, z) E_{0} / V_{0} ; \Phi=\phi(L / 2,0, z) / V_{0} ; T_{11}=\sigma_{11}(L / 2,0, z) h E_{0} /\left(C_{00} V_{0}\right)$ where $V_{0}=100 \mathrm{~V}$ ) obtained through the thickness of the simply supported piezoelectric beam using present element are shown in Figures 3(a) and (b) along with the exact analytical solutions 

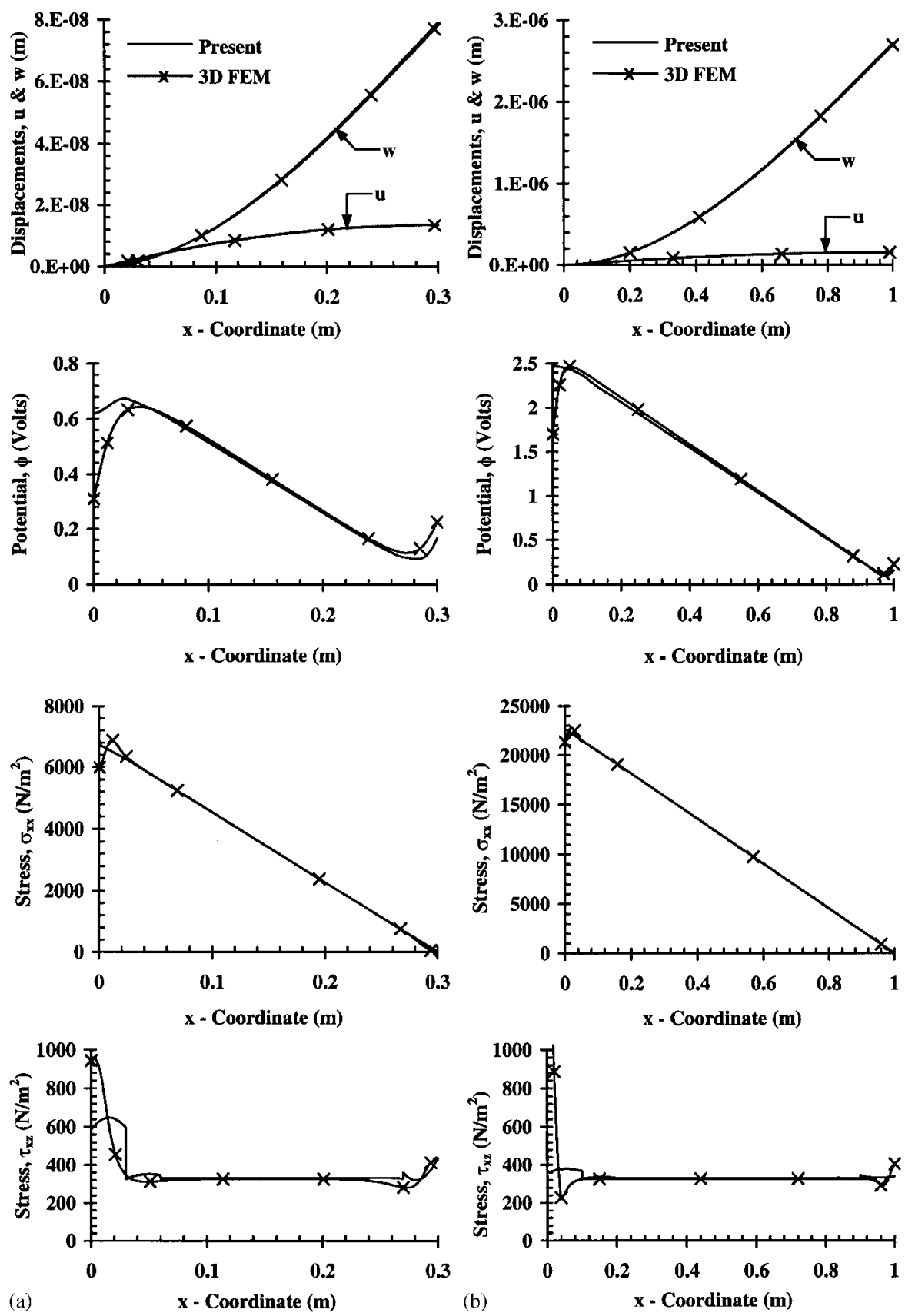

Figure 5. Distribution of displacements, electrical potential and stress along length (at $z=-0.0375$ ) due to $1 \mathrm{~N}$ transverse tip load in Problem No. 2: (a) length to thickness ratio $(L / h)=3$ (left side); and (b) $L / h=10$ (right side). 


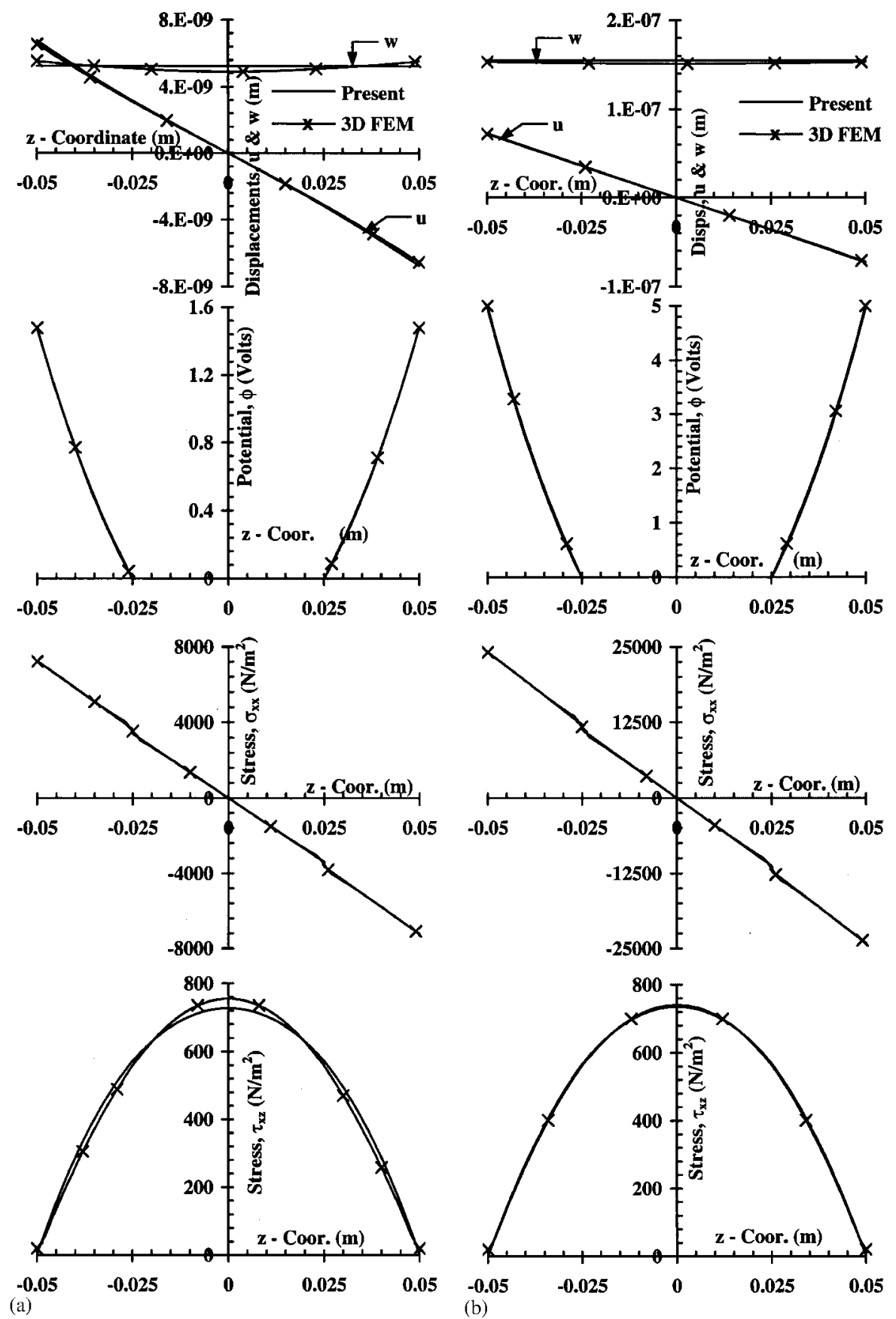

Figure 6. Distribution of displacements, electrical potential and stresses along the thickness (at $x / L=0.2$ ) due to $1 \mathrm{~N}$ transverse tip load in Problem No. 2: (a) length to thickness ratio $(L / h)=3$ (left side); and (b) $L / h=10$ (right side). 

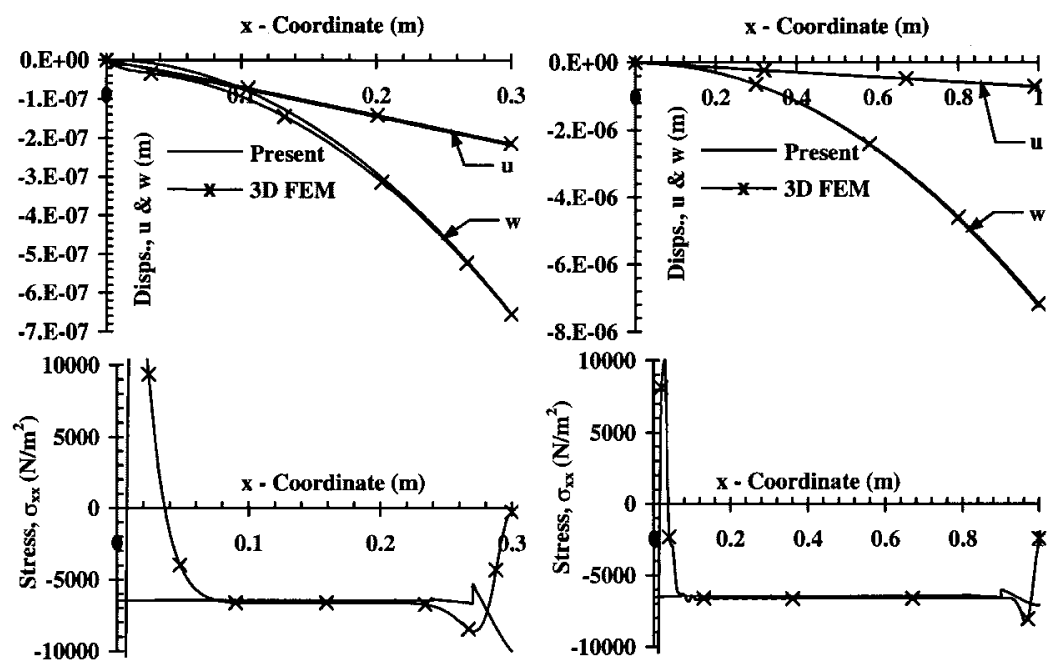

(a)

(b)

Figure 7. Distribution of displacements and stresses along length (at $z=-0.05 \mathrm{~m}$ ) due to electrical load in Problem No. 2: (a) length tothickness ratio $(L / h)=3$ (left side); and (b) $L / h=10$ (right side).
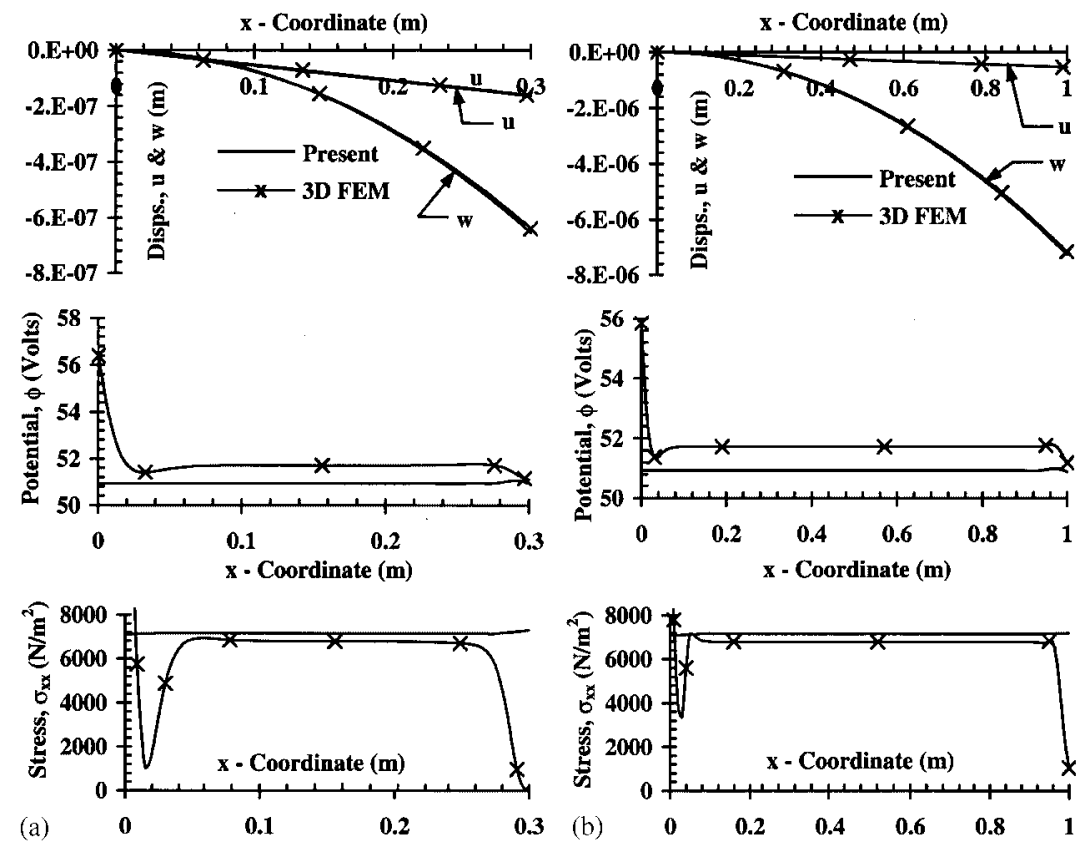

Figure 8. Distribution of displacements, electrical potential and stresses along length (at $z=-0.0375 \mathrm{~m}$ ) due to electrical load in Problem No. 2: (a) length to thickness ratio $(L / h)=3$ (left side); and (b) $L / h=10$ (right side). 

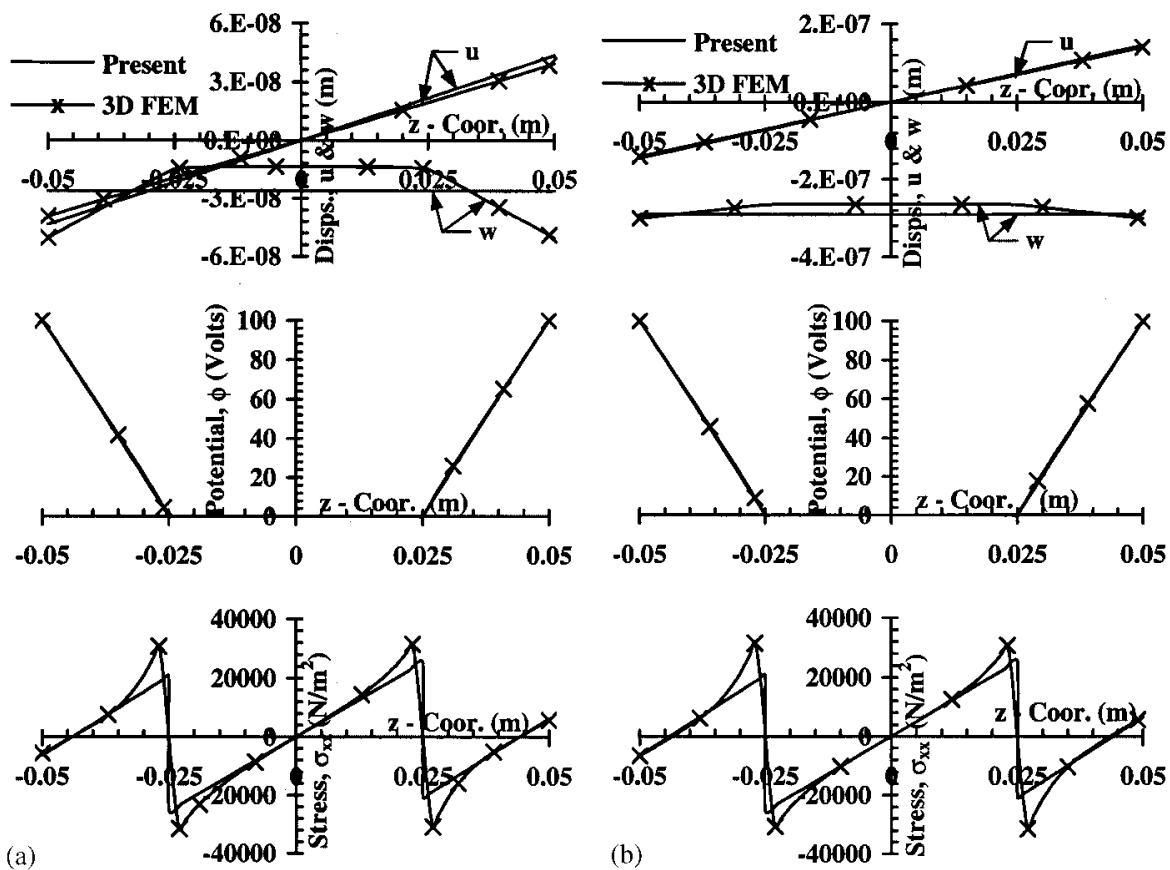

Figure 9. Distribution of displacements, electrical potential and stress along thickness (at $x / L=0.2)$ due to electrical load in Problem No. 2: (a) length to thickness ratio $(L / h)=3$ (left side); and (b) $L / h=10$ (right side).

[15] for both thick and thin cases $(L / h=10,50)$. The present model predicts the solutions accurately and they match very well with the available analytical results. It is further inferred from Figure 3(b) that the element does not lock and free from locking phenomenon, irrespective of the type of loading.

Next, a cantilever piezoelectric composite beam is examined considering two values for length-to thickness ratio $(L / h=3,10)$ for the bending characteristics under mechanical and electrical loads (Problem 2). A tip load of $1 \mathrm{~N}$ is considered for mechanical load whereas the potential of $100 \mathrm{~V}$ at the top and bottom surfaces of the beam is assumed for electrical case. Furthermore, the electrical potentials in the core as well as along the interfaces of the laminated beam are taken as zero, irrespective of loading cases. The convergence study made by varying the number of elements in the thickness of piezoelectric layers (skins), to take into account the appropriate variation in electrical potential, and along the length of the beam is presented in Tables I and II. It is noticed from these tables that the number of elements required for displacement convergence is less compared to that of stress evaluation, as expected. It is further seen from these tables that the idealization of 1-element in the thickness (each skin) and 12-element along the length yields the converged solutions for the problem considered here. The response characteristics pertaining to in-plane and lateral displacements, electric potential, normal and transverse stresses along the length (on the free surface and within the piezoelectric layer) and thickness (near the fixed support) directions of the beam calculated based on such mesh are highlighted in Figures 4-6 for mechanical load. Similar study is made for electrical 

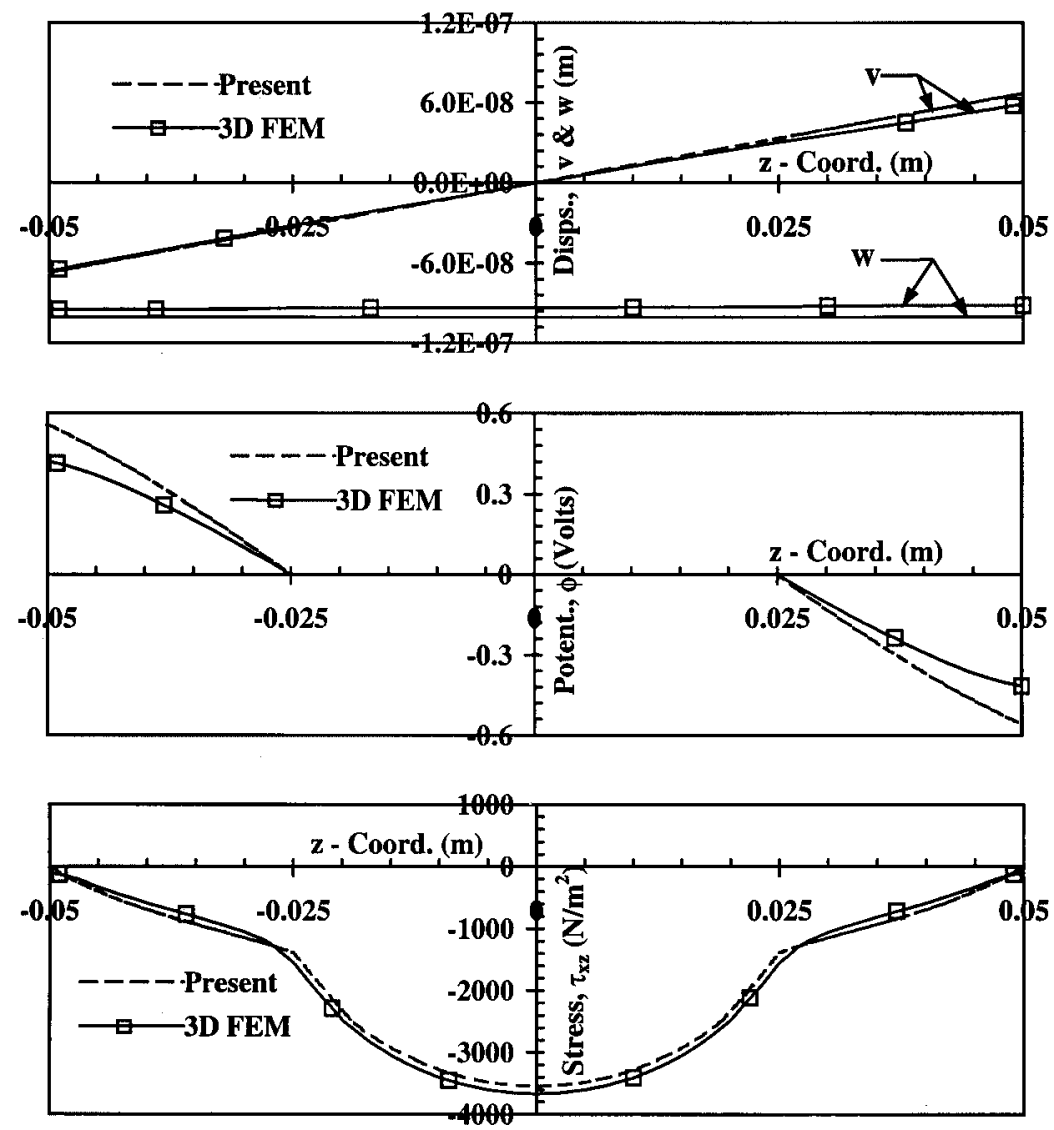

Figure 10. Distribution of displacements, electrical potential and stress along the thickness [at $(x, y)=(0.5 \mathrm{~m}, 0.075 \mathrm{~m})]$ due to $1 \mathrm{Nm}$ torque applied at free end in Problem No. 3 .

loading situation and the results are described in Figures 7-9. All these results evaluated here are compared with those of three-dimensional finite element model from ANSYS 5.6. It can be observed from these figures that the performance of the present element is, in general, very good except near the fixed support and free end of the beam. Near the fixed support and free end, the results, in particular, stresses and potential predicted by the present one-dimensional model have not matched well with those of the three-dimensional model. However, the discrepancy associated with the displacement values is not very significant. The difference in the results near the clamped/free ends of the beam may be attributed to the existence of three-dimensional state of stress near these locations whereas the present structural model is based on one-dimensional approximation. For certain cases, the changes in the trends of variation of potential and stresses along the length is observed near the support/free ends which may be possibly due to the boundary layer effects. It can be noted here that the beam element with two-dimensional representation ( $x$ and $z$ directions) of electrical field is sufficient for the bending analysis. It is apt to make a brief mention here about the mesh size used for the three-dimensional study 
Table III. Convergence for No. of elements along thickness in each skin layer (Nesk) for Problem No. 3 (No. of terms in the warp. Func. $N=12$, No. of elements along the width direction $=6$ ).

\begin{tabular}{|c|c|c|c|c|c|c|c|c|}
\hline Nesk & $u(\mathrm{~m})$ & $v(\mathrm{~m})$ & $w(\mathrm{~m})$ & $\phi(\mathrm{V})$ & $\sigma_{x x}\left(\mathrm{~N} / \mathrm{m}^{2}\right)$ & $\tau_{x y}\left(\mathrm{~N} / \mathrm{m}^{2}\right)$ & $\tau_{x z}\left(\mathrm{~N} / \mathrm{m}^{2}\right)$ & $\tau_{x z}^{*}\left(\mathrm{~N} / \mathrm{m}^{2}\right)$ \\
\hline 1 & 1.137E-09 & $-6.694 \mathrm{E}-08$ & $-1.004 \mathrm{E}-07$ & 1.423 & 852.3 & -2040 & -3484 & -1333 \\
\hline 2 & $1.136 \mathrm{E}-09$ & $-6.694 \mathrm{E}-08$ & $-1.004 \mathrm{E}-07$ & 1.423 & 854.4 & -2045 & -3492 & -1342 \\
\hline 4 & $1.135 \mathrm{E}-09$ & $-6.694 \mathrm{E}-08$ & $-1.004 \mathrm{E}-07$ & 1.423 & 856 & -2049 & -3491 & -1341 \\
\hline 6 & $1.135 \mathrm{E}-09$ & $-6.694 \mathrm{E}-08$ & $-1.004 \mathrm{E}-07$ & 1.423 & 856.3 & -2050 & -3491 & -1341 \\
\hline
\end{tabular}

$(x, y, z)$ location for $u=(0.5 \mathrm{~m}, 0.075 \mathrm{~m}, 0.05 \mathrm{~m}),(x, y, z)$ location for $v=(0.5 \mathrm{~m}, 0.0,-0.05 \mathrm{~m}),(x, y, z)$ location for $w=(0.5 \mathrm{~m}, 0.075 \mathrm{~m}, 0.0),(x, y, z)$ location for $\phi, \sigma_{x x}$ and $\tau_{x y}=(0.5 \mathrm{~m}, 0.0,-0.05 \mathrm{~m}),(x, y, z)$ location for $\tau_{x z}=(0.5 \mathrm{~m}, 0.075 \mathrm{~m}, 0.0),(x, y, z)$ location for $\tau_{x z}^{*}=(0.5 \mathrm{~m}, 0.075 \mathrm{~m},-0.05 \mathrm{~m})$.

Table IV. Convergence test for number of terms $(N)$ in the warping function for Problem No. 3 (No. of elements in the width direction $=6$, No.of elements along thickness in each skin=4).

\begin{tabular}{|c|c|c|c|c|c|c|c|c|}
\hline$N$ & $u(\mathrm{~m})$ & $v(\mathrm{~m})$ & $w(\mathrm{~m})$ & $\phi(\mathrm{V})$ & $\sigma_{x x}\left(\mathrm{~N} / \mathrm{m}^{2}\right)$ & $\tau_{x y}\left(\mathrm{~N} / \mathrm{m}^{2}\right)$ & $\tau_{x z}\left(\mathrm{~N} / \mathrm{m}^{2}\right)$ & $\tau_{x z}^{*}\left(\mathrm{~N} / \mathrm{m}^{2}\right)$ \\
\hline 2 & 9.304E-10 & $-6.695 \mathrm{E}-08$ & $-1.004 \mathrm{E}-07$ & 1.397 & 821.1 & -1969 & -2473 & -992.9 \\
\hline 4 & $1.090 \mathrm{E}-09$ & $-6.695 \mathrm{E}-08$ & $-1.004 \mathrm{E}-07$ & 1.419 & 847.2 & -2029 & -3071 & -1207 \\
\hline 6 & 1.119E-09 & $-6.695 \mathrm{E}-08$ & $-1.004 \mathrm{E}-07$ & 1.422 & 852.1 & -2040 & -3283 & -1276 \\
\hline 8 & $1.129 \mathrm{E}-09$ & $-6.694 \mathrm{E}-08$ & $-1.004 \mathrm{E}-07$ & 1.422 & 854.2 & -2045 & -3387 & -1308 \\
\hline 10 & $1.133 \mathrm{E}-09$ & $-6.694 \mathrm{E}-08$ & $-1.004 \mathrm{E}-07$ & 1.423 & 854.8 & -2046 & -3450 & -1329 \\
\hline 12 & $1.135 \mathrm{E}-09$ & $-6.694 \mathrm{E}-08$ & $-1.004 \mathrm{E}-07$ & 1.423 & 856 & -2049 & -3491 & -1341 \\
\hline 14 & $1.135 \mathrm{E}-09$ & $-6.694 \mathrm{E}-08$ & $-1.004 \mathrm{E}-07$ & 1.423 & 856 & -2049 & -3516 & -1345 \\
\hline
\end{tabular}

$(x, y, z)$ location for $u=(0.5 \mathrm{~m}, 0.075 \mathrm{~m}, 0.05 \mathrm{~m}),(x, y, z)$ location for $v=(0.5 \mathrm{~m}, 0.0,-0.05 \mathrm{~m}),(x, y, z)$ location for $w=(0.5 \mathrm{~m}, 0.075 \mathrm{~m}, 0.0),(x, y, z)$ location for $\phi, \sigma_{x x}$ and $\tau_{x y}=(0.5 \mathrm{~m}, 0.0,-0.05 \mathrm{~m}),(x, y, z)$ location for $\tau_{x z}=(0.5 \mathrm{~m}, 0.075 \mathrm{~m}, 0.0),(x, y, z)$ location for $\tau_{x z}^{*}=(0.5 \mathrm{~m}, 0.075 \mathrm{~m},-0.05 \mathrm{~m})$.

Table V. Convergence test for number of elements in the width direction (Ney) for Problem No. 3 (No. of terms in the warp. Func. $N=12$, No. of elements along the thickness in each skin layer=4).

\begin{tabular}{|c|c|c|c|c|c|c|c|c|}
\hline Ney & $u(\mathrm{~m})$ & $v(\mathrm{~m})$ & $w(\mathrm{~m})$ & $\phi(\mathrm{V})$ & $\sigma_{x x}\left(\mathrm{~N} / \mathrm{m}^{2}\right)$ & $\tau_{x y}\left(\mathrm{~N} / \mathrm{m}^{2}\right)$ & $\tau_{x z}\left(\mathrm{~N} / \mathrm{m}^{2}\right)$ & $\tau_{x z}^{*}\left(\mathrm{~N} / \mathrm{m}^{2}\right)$ \\
\hline 1 & 1.137E-09 & $-6.696 \mathrm{E}-08$ & $-1.004 \mathrm{E}-07$ & 1.427 & 865.2 & -2073 & -3536 & -1384 \\
\hline 2 & 1.137E-09 & $-6.695 \mathrm{E}-08$ & $-1.004 \mathrm{E}-07$ & 1.426 & 847.1 & -2025 & -3538 & -1387 \\
\hline 4 & $1.136 \mathrm{E}-09$ & $-6.694 \mathrm{E}-08$ & $-1.004 \mathrm{E}-07$ & 1.422 & 855.3 & -2047 & -3515 & -1365 \\
\hline 6 & $1.135 \mathrm{E}-09$ & $-6.694 \mathrm{E}-08$ & $-1.004 \mathrm{E}-07$ & 1.423 & 856 & -2049 & -3491 & -1341 \\
\hline 8 & $1.135 \mathrm{E}-09$ & $-6.694 \mathrm{E}-08$ & $-1.004 \mathrm{E}-07$ & 1.423 & 856.1 & -2049 & -3474 & -1324 \\
\hline
\end{tabular}

$(x, y, z)$ location for $u=(0.5 \mathrm{~m}, 0.075 \mathrm{~m}, 0.05 \mathrm{~m}),(x, y, z)$ location for $v=(0.5 \mathrm{~m}, 0.0,-0.05 \mathrm{~m}),(x, y, z)$ location for $w=(0.5 \mathrm{~m}, 0.075 \mathrm{~m}, 0.0),(x, y, z)$ location for $\phi, \sigma_{x x}$ and $\tau_{x y}=(0.5 \mathrm{~m}, 0.0,-0.05 \mathrm{~m}),(x, y, z)$ location for $\tau_{x z}=(0.5 \mathrm{~m}, 0.075 \mathrm{~m}, 0.0),(x, y, z)$ location for $\tau_{x z}^{*}=(0.5 \mathrm{~m}, 0.075 \mathrm{~m},-0.05 \mathrm{~m})$.

of this problem. Based on 8-noded brick element (4-degrees of freedom per node) the beam is modelled using $40 \times 1$ mesh discretization along length and width directions, and 10 elements in each skin (piezoelectric layer) and 20 elements in the core along the thickness direction.

Finally, the torsional characteristics of the piezoelectric beam is analysed considering a cantilever with geometrical parameters and material properties given in Problem 3 for both 

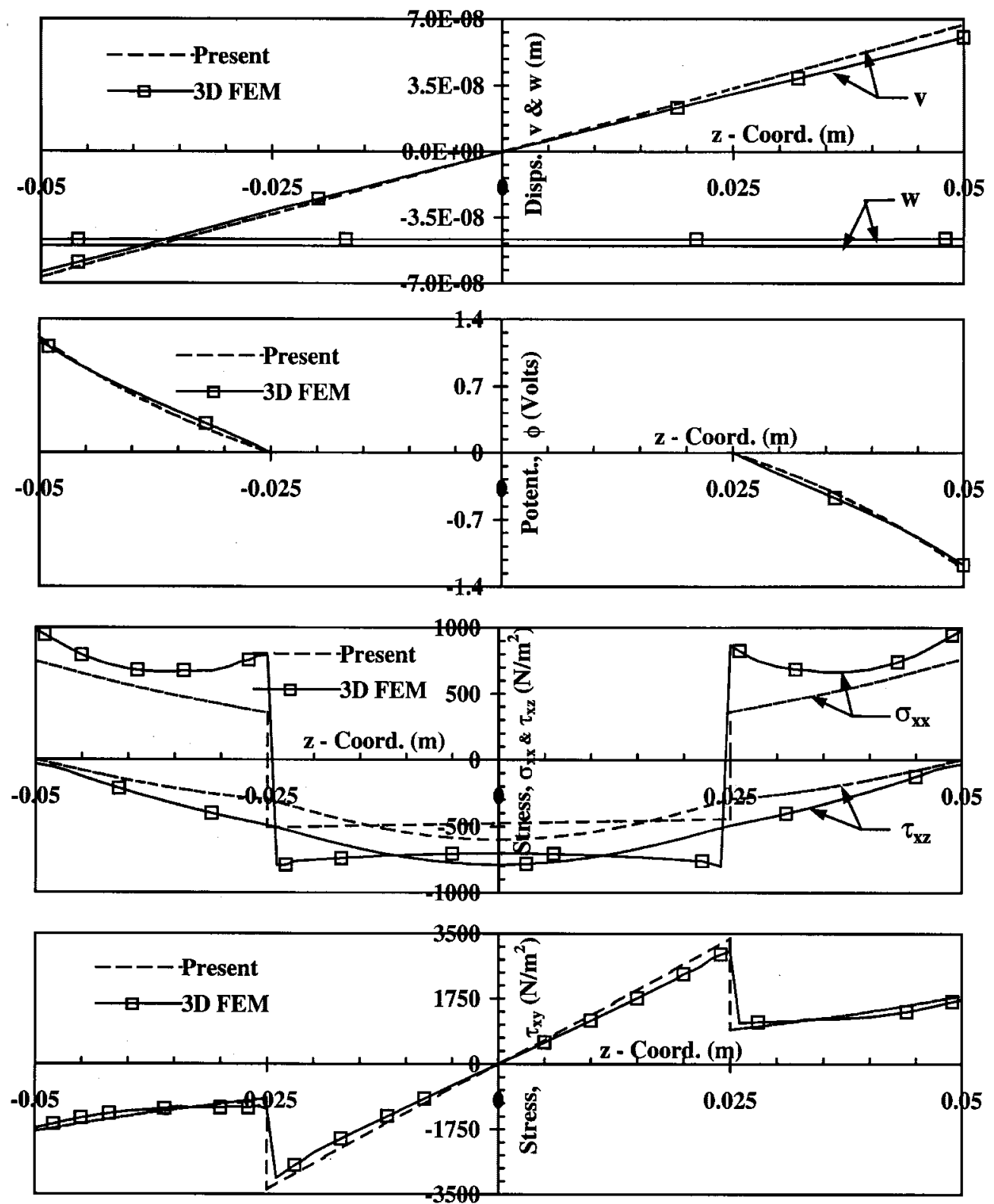

Figure 11. Distribution of displacements, electrical potential and stresses along the thickness [at $(x, y)=(0.5 \mathrm{~m}, 0.0375 \mathrm{~m})]$ due to $1 \mathrm{Nm}$ torque applied at free end in Problem No. 3 . 

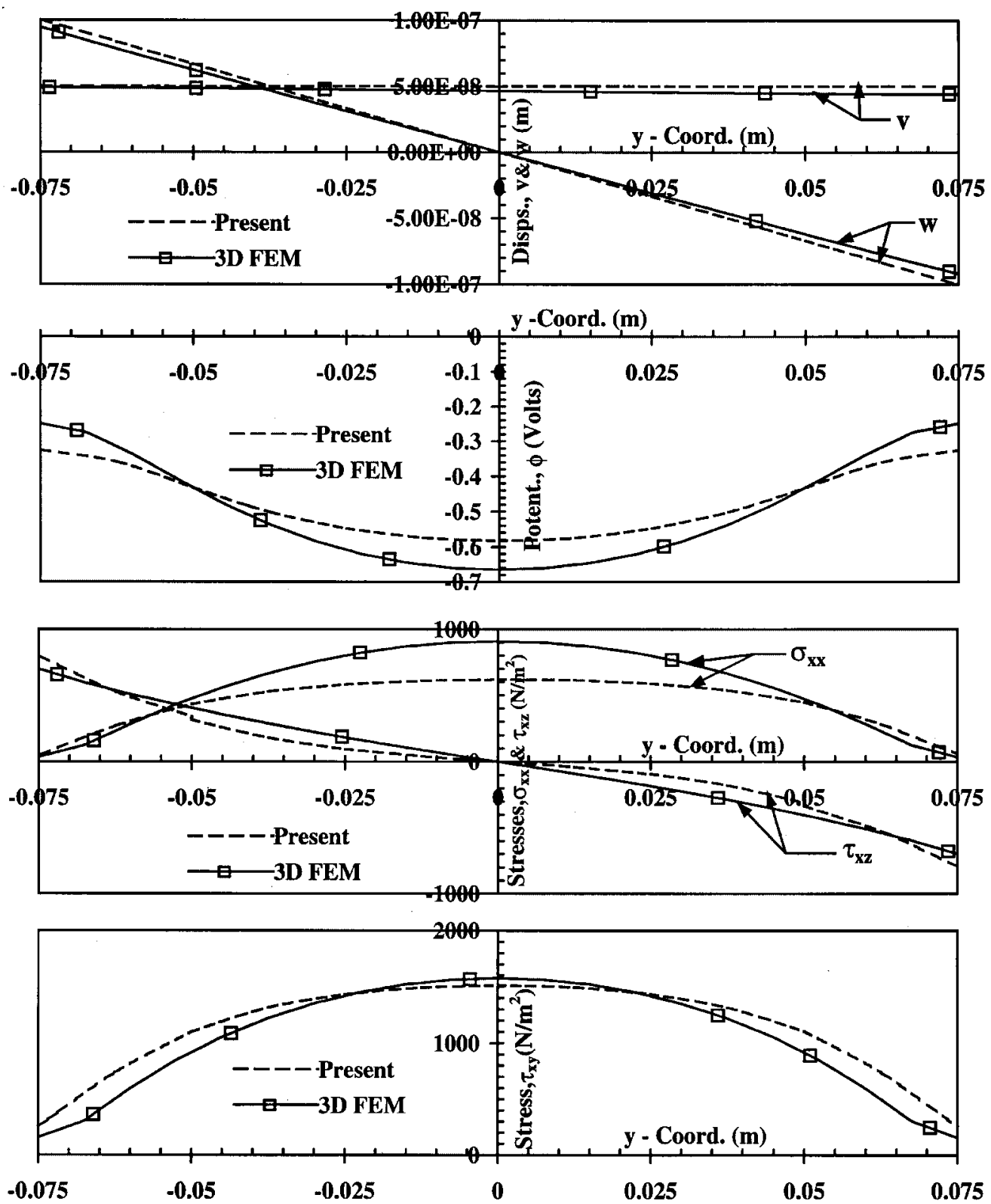

Figure 12. Distribution of displacements, electrical potential and stresses along the width [at $(x, z)=(0.5 \mathrm{~m}, 0.0375 \mathrm{~m})]$ due to $1 \mathrm{Nm}$ torque applied at free end in Problem No. 3. 

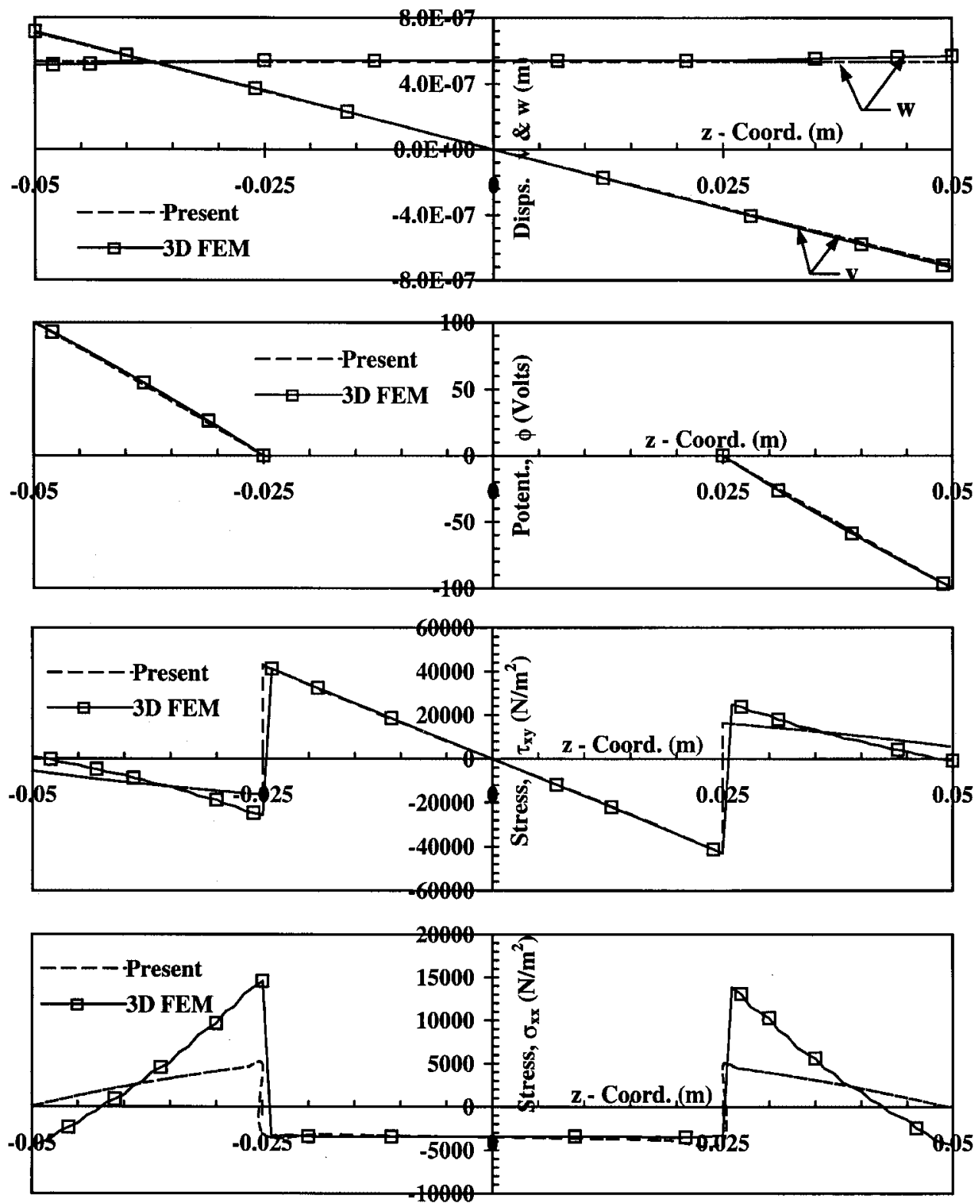

Figure 13. Distribution of displacements, electrical potential and stresses along the thickness [at $(x, y)=(0.5 \mathrm{~m}, 0.0375 \mathrm{~m})]$ due to electrical load in Problem No. 3 . 
mechanical and electrical loading situations. Unlike in Problems 1 and 2, here, the skins are treated as PZT/Epoxy layers. The lamination scheme considered for this case is $-45^{\circ}$ (bottom skin) $/ 0^{\circ}$ (core) $/ 45^{\circ}$ (top skin). A torque of $1 \mathrm{Nm}$ is assumed at the free end of the cantilever beam for mechanical case whereas the electrical potential of $100 \mathrm{~V}$ at the bottom surface of the beam and $-100 \mathrm{~V}$ at the top surface of the beam are considered for electrical loading case. The electrical potential conditions in the core and along the interfaces of the laminate are treated as zero values for all the analyses. Detailed convergence study is conducted by increasing the number of elements in the thickness as well as width directions, and also increasing number of terms in the warping function, and the results are tabulated in Tables III-V. It can be opined from these tables that 14-term in the warping function in conjunction with 4- and 6-element idealization along the thickness and width of the each piezoelectric layers of sandwich beam, respectively, are required for the accurate prediction of the various deflections and stresses. For the length direction, 8-element idealization gives converged results and, for the sake of brevity, these details are not shown here. The numerical results generated here along the thickness (at $x / L=0.5, y / b=0.5,0.25$ ) and width (at $x / L=0.5, z / h=0.375$ ) directions of the beam are plotted in Figures 10-13 and compared with those of three-dimensional finite element model using ANSYS 5.6. Furthermore, the present model exhibits the presence of axial stress due to the torsional load and this is due to the fact that the formulation accounts for the constrained torsion. It is revealed from these figures that the results predicted by the present element are, in general, fairly good agreement with three-dimensional solution. Some differences noticed in the results between the present one and 3D model for the distributions of stress/potential fields may be attributed to the presence of three-dimensional state of stress/potential distributions for this class of problem whereas the element treated here is essentially based on one-dimensional structural approximation. It is worthwhile again giving the details of the mesh using 8-noded brick element (with 4-DOF per node) for 3D modelling of this problem from ANSYS. The beam for the torsional analysis is discretized, using $20 \times 30$ mesh along length and width directions, 20 elements in each skin (piezoelectric layer) and 40 elements in the core along the thickness direction.

It is apt to mention here that the converged mesh of the present element results in about 500 degrees of freedom for bending problems and about 3700 for torsional problems. Whereas, the converged mesh of 3D finite elements yields about 13000 and 200000 degrees of freedom for bending and torsion examples, respectively. This is the major difference between these models for the problems solved here. Thus, it may be concluded that the present model is computationally very efficient for the accuracy achieved here.

\section{CONCLUSIONS}

A new beam finite element to analyse laminated/sandwich piezoelectric structures has been constructed using refined shear deformation theory and including torsion warping under the more general constrained torsion formulation. Nonlinear variation of electrical field is assumed in all the directions. The element derived here exhibits good convergence and free of shear locking syndrome. Some of the general observations made through this study are:

1. The present element, in general, performs well for both flexural and torsional behaviours of laminated piezoelectric beam with rectangular cross-section. 
2. The prediction of electrical potential distribution and transverse shear/axial stresses under mechanical load are accurate for simply supported case whereas, except the free ends and fixed support, the results are in good agreement with three-dimensional solutions for cantilever case.

3. The presence of axial stress while beam under torsional load is brought out as the formulation includes the constrained torsion.

4. The problems with variation of electrical potential field in all the three directions can be analysed using the present model.

5. For the given accuracy, the present element results in significant reduction in computational time and memory requirements.

\section{APPENDIX A}

The various matrices involved in Equation (11) are

$$
\begin{aligned}
& {\left[B_{u}\right]=\left[\begin{array}{llllllllllll}
n_{1, x} & 0 & 0 & 0 & 0 & 0 & 0 & 0 & 0 & 0 & 0 & 0 \\
0 & -\bar{h}_{1, x x} & -\bar{h}_{2, x x} & 0 & 0 & 0 & 0 & 0 & 0 & 0 & 0 & 0 \\
0 & \bar{h}_{1, x x} & \bar{h}_{2, x x} & 0 & 0 & 0 & s_{1, x} & 0 & 0 & 0 & s_{2, x} & 0 \\
0 & 0 & 0 & -\bar{h}_{1, x x} & -\bar{h}_{2, x x} & 0 & 0 & 0 & 0 & 0 & 0 & 0 \\
0 & 0 & 0 & \bar{h}_{1, x x} & \bar{h}_{2, x x} & s_{1, x} & 0 & 0 & 0 & s_{2, x} & 0 & 0 \\
0 & \bar{h}_{1, x} & \bar{h}_{2, x} & 0 & 0 & 0 & s_{1} & 0 & 0 & 0 & s_{2} & 0 \\
0 & 0 & 0 & \bar{h}_{1, x} & \bar{h}_{2, x} & s_{1} & 0 & 0 & 0 & s_{2} & 0 & 0 \\
0 & 0 & 0 & 0 & 0 & 0 & 0 & s_{1, x} & 0 & 0 & 0 & s_{2, x} \\
0 & 0 & 0 & 0 & 0 & 0 & 0 & 0 & n_{1} & 0 & 0 & 0 \\
0 & 0 & 0 & 0 & 0 & 0 & 0 & 0 & n_{1, x} & 0 & 0 & 0
\end{array}\right.} \\
& \begin{array}{lllllllll}
n_{2, x} & 0 & 0 & 0 & 0 & 0 & 0 & 0 & 0 \\
0 & -\bar{h}_{3, x x} & -\bar{h}_{4, x x} & 0 & 0 & 0 & 0 & 0 & 0 \\
0 & \bar{h}_{3, x x} & \bar{h}_{4, x x} & 0 & 0 & 0 & s_{3, x} & 0 & 0
\end{array} \\
& \begin{array}{llllllll}
0 & 0 & 0 & -\bar{h}_{3, x x}-\bar{h}_{4, x x} & 0 & 0 & 0 & 0
\end{array} \\
& \begin{array}{lllllllll}
0 & 0 & 0 & \bar{h}_{3, x x} & \bar{h}_{4, x x} & s_{3, x} & 0 & 0 & 0
\end{array} \\
& \begin{array}{lllllllll}
0 & \bar{h}_{3, x} & \bar{h}_{4, x} & 0 & 0 & 0 & s_{3} & 0 & 0
\end{array} \\
& \begin{array}{lllllllll}
0 & 0 & 0 & \bar{h}_{3, x} & \bar{h}_{4, x} & s_{3} & 0 & 0 & 0
\end{array} \\
& \begin{array}{lllllllll}
0 & 0 & 0 & 0 & 0 & 0 & 0 & s_{3, x} & 0
\end{array} \\
& \begin{array}{llllllllll}
0 & 0 & 0 & 0 & 0 & 0 & 0 & 0 & n_{2}
\end{array} \\
& \begin{array}{lllllllll}
0 & 0 & 0 & 0 & 0 & 0 & 0 & 0 & n_{2, x}
\end{array}
\end{aligned}
$$




$$
\left[H_{u}\right]=\left[\begin{array}{lllllllllllllllllllll}
n_{1} & 0 & 0 & 0 & 0 & 0 & 0 & 0 & 0 & 0 & 0 & 0 & n_{2} & 0 & 0 & 0 & 0 & 0 & 0 & 0 & 0 \\
0 & \bar{h}_{1} & \bar{h}_{2} & 0 & 0 & 0 & 0 & 0 & 0 & 0 & 0 & 0 & 0 & \bar{h}_{3} & \bar{h}_{4} & 0 & 0 & 0 & 0 & 0 & 0 \\
0 & 0 & 0 & \bar{h}_{1} & \bar{h}_{2} & 0 & 0 & 0 & 0 & 0 & 0 & 0 & 0 & 0 & 0 & \bar{h}_{3} & \bar{h}_{4} & 0 & 0 & 0 & 0 \\
0 & 0 & 0 & 0 & 0 & s_{1} & 0 & 0 & 0 & s_{2} & 0 & 0 & 0 & 0 & 0 & 0 & 0 & s_{3} & 0 & 0 & 0 \\
0 & 0 & 0 & 0 & 0 & 0 & s_{1} & 0 & 0 & 0 & s_{2} & 0 & 0 & 0 & 0 & 0 & 0 & 0 & s_{3} & 0 & 0 \\
0 & 0 & 0 & 0 & 0 & 0 & 0 & s_{1} & 0 & 0 & 0 & s_{2} & 0 & 0 & 0 & 0 & 0 & 0 & 0 & s_{3} & 0
\end{array}\right]
$$

where $\left(n_{1}, n_{2}\right),\left(s_{1}, s_{2}, s_{3}\right)$ and $\left(\bar{h}_{1}, \bar{h}_{2}, \bar{h}_{3}, \bar{h}_{4}\right)$ are the set of shape functions (linear, quadratic and Hermite) used for interpolating the structural field variables $\left[(u, \gamma),\left(\theta_{x}, \theta_{y}, \theta\right)\right.$ and $(v, w)$, respectively. They are defined as

$$
\begin{aligned}
& n_{1}=1-\left(x-x_{1}\right) / L^{e}, \quad n_{2}=\left(x-x_{1}\right) / L^{e} \\
& s_{1}=1-3\left(x-x_{1}\right) / L^{e}+2\left(\frac{x-x_{1}}{L^{e}}\right)^{2}, \quad s_{2}=4\left(x-x_{1}\right) / L^{e}-4\left(\frac{x-x_{1}}{L^{e}}\right)^{2}, \\
& s_{3}=-\left(x-x_{1}\right) / L^{e}+2\left(\frac{x-x_{1}}{L^{e}}\right)^{2} \\
& \bar{h}_{1}=1-3\left(\frac{x-x_{1}}{L^{e}}\right)^{2}+2\left(\frac{x-x_{1}}{L^{e}}\right)^{3}, \quad \bar{h}_{2}=\left(x-x_{1}\right)\left(1-\frac{x-x_{1}}{L^{e}}\right)^{2}, \\
& \bar{h}_{3}=3\left(\frac{x-x_{1}}{L^{e}}\right)^{2}-2\left(\frac{x-x_{1}}{L^{e}}\right)^{3}, \quad \bar{h}_{4}=\left(x-x_{1}\right)\left[\left(\frac{x-x_{1}}{L^{e}}\right)^{2}-\frac{x-x_{1}}{L^{e}}\right]
\end{aligned}
$$

Here, $x_{1}$ is the global $x$ co-ordinate of first node of an element.

The vector of elemental structural degrees of freedom is denoted as

$\left\{\delta_{u}^{e}\right\}^{\mathrm{T}}=\left\{\begin{array}{lllllllllllllllllllllll}u_{01} & v_{01} & v_{0, x 1} & w_{01} & w_{0, x 1} & \theta_{x 1} & \theta_{y 1} & \theta_{1} & \gamma_{1} & \theta_{x 2} & \theta_{y 2} & \theta_{2} & u_{03} & v_{03} & v_{0, x 3} & w_{03} & w_{0, x 3} & \theta_{x 3} & \theta_{y 3} & \theta_{3} & \gamma_{3}\end{array}\right\}$

\section{APPENDIX B}

The matrices involved while defining the electrical field intensities in Equations (12) are

$$
\left[\bar{Z}_{\phi}\right]=\left[\begin{array}{llllllllllllllllll}
l_{1} & l_{2} & l_{3} & l_{4} & l_{5} & l_{6} & l_{7} & l_{8} & l_{9} & 0 & 0 & 0 & 0 & 0 & 0 & 0 & 0 & 0 \\
0 & 0 & 0 & 0 & 0 & 0 & 0 & 0 & 0 & l_{1, y} & l_{2, y} & l_{3, y} & l_{4, y} & l_{5, y} & l_{6, y} & l_{7, y} & l_{8, y} & l_{9, y} \\
0 & 0 & 0 & 0 & 0 & 0 & 0 & 0 & 0 & l_{1, z} & l_{2, z} & l_{3, z} & l_{4, z} & l_{5, z} & l_{6, z} & l_{7, z} & l_{8, z} & l_{9, z}
\end{array}\right]
$$


The non-zero elements of matrix $\left[B_{\phi}\right]$ are

$$
\begin{gathered}
B_{\phi}(i, i)=s_{1, x}, \quad B_{\phi}(i, i+9)=s_{2, x}, \quad B_{\phi}(i, i+18)=s_{3, x} \\
B_{\phi}(i+9, i)=s_{1}, \quad B_{\phi}(i+9, i+9)=s_{2}, \quad B_{\phi}(i+9, i+18)=s_{3} \quad(i=1,2, \ldots, 9)
\end{gathered}
$$

The shape functions $\left(l_{1}, l_{2}, \ldots, l_{9}\right)$ which are expressed as the product of quadratic Lagrangian polynomials in $y\left(n_{i}^{y}, i=1,2,3\right)$ and $z\left(n_{i}^{z}\right)$ directions, and $\left(s_{1}, s_{2}, s_{3}\right)$ quadratic shape functions along the length $(x)$ employed for the interpolation of electrical potential field are

$$
\begin{aligned}
& l_{1}=n_{1}^{y} n_{1}^{z}, \quad l_{2}=n_{2}^{y} n_{1}^{z}, \quad l_{3}=n_{3}^{y} n_{1}^{z}, \quad l_{4}=n_{1}^{y} n_{2}^{z}, \quad l_{5}=n_{2}^{y} n_{2}^{z}, \quad l_{6}=n_{3}^{y} n_{2}^{z}, \\
& l_{7}=n_{1}^{y} n_{3}^{z}, \quad l_{8}=n_{2}^{y} n_{3}^{z}, \quad l_{9}=n_{3}^{y} n_{3}^{z} \\
& n_{1}^{y}=1-3\left(y-y_{1}\right) / b^{e}+2\left(\frac{y-y_{1}}{b^{e}}\right)^{2}, \quad n_{2}^{y}=4\left(y-y_{1}\right) / b^{e}-4\left(\frac{y-y_{1}}{b^{e}}\right)^{2}, \\
& n_{3}^{y}=-\left(y-y_{1}\right) / b^{e}+2\left(\frac{y-y_{1}}{b^{e}}\right)^{2} \\
& n_{1}^{z}=1-3\left(z-z_{1}\right) / h^{e}+2\left(\frac{z-z_{1}}{h^{e}}\right)^{2}, \quad n_{2}^{z}=4\left(z-z_{1}\right) / h^{e}-4\left(\frac{z-z_{1}}{h^{e}}\right)^{2}, \\
& n_{3}^{z}=-\left(z-z_{1}\right) / h^{e}+2\left(\frac{z-z_{1}}{h^{e}}\right)^{2} \\
& s_{1}=1-3\left(x-x_{1}\right) / L^{e}+2\left(\frac{x-x_{1}}{L^{e}}\right)^{2}, \quad s_{2}=4\left(x-x_{1}\right) / L^{e}-4\left(\frac{x-x_{1}}{L^{e}}\right)^{2}, \\
& s_{3}=-\left(x-x_{1}\right) / L^{e}+2\left(\frac{x-x_{1}}{L^{e}}\right)^{2}
\end{aligned}
$$

Here, $\left(x_{1}, y_{1}, z_{1}\right)$ are the global co-ordinates of first node of an element.

The vector of element level electrical potential degrees of freedom is described as

$$
\begin{aligned}
&\left\{\delta_{\phi}^{e}\right.\}^{\mathrm{T}}= \\
&\left\{\begin{array}{llllllllllllll}
\phi_{1} & \phi_{2} & \phi_{3} & \phi_{4} & \phi_{5} & \phi_{6} & \phi_{7} & \phi_{8} & \phi_{9} & \phi_{10} & \phi_{11} & \phi_{12} & \phi_{13} & \phi_{14} \\
& \phi_{15} & \phi_{16} & \phi_{17} & \phi_{18} & \phi_{19} & \phi_{20} & \phi_{21} & \phi_{22} & \phi_{23} & \phi_{24} & \phi_{25} & \phi_{26} & \phi_{27}
\end{array}\right\}
\end{aligned}
$$




\section{ACKNOWLEDGEMENTS}

This study was supported by Indo French Centre for the Promotion of Advanced Research (Centre Franco-Indien Pour La Promotion De La Recherche Avancee), Department of Science \& Technology, Government of India, through the grant of Project No. 2308-1.

\section{REFERENCES}

1. Tang YY, Noor AK, Xu K. Assessment of computational models for thermoelectroelastic multilayered plates. Computers and Structures 1996; 61:915-933.

2. Saravanos DA, Heyliger PR. Mechanics and computational models for laminated piezoelectric beams, plates, and shells. ASME, Applied Mechanics Review 1999; 52:305-320.

3. Sunar M, Rao SS. Recent advances in sensing and control of flexible structures via piezoelectric materials technology. ASME, Applied Mechanics Review 1999; 52:1-16.

4. Benjeddou A. Advances in piezoelectric finite element modeling of adoptive structural elements: a survey. Computers and Structures 2002; 76:347-363.

5. Ray MC, Bhattacharyya R, Samanta B. Static analysis of an intelligent structures by the finite element method. Computers and Structures 1994; 52:617-631.

6. Batra RC, Vidoli S. Higher-order piezoelectric plate theory derived from a three-dimensional variational principle. AIAA Journal 2002; 40:91-104.

7. Yang JS. Equations for thick elastic plates with partially electroded piezoelectric actuators and higher order electric fields. Smart Materials and Structures 1999; 8:83-91.

8. Bisegna P, Caruso G, Maceri F. A layer-wise Reissner-Mindlin-type model for the vibration analysis and suppression of piezoactuated plates. Computers and Structures 2001; 79:2309-2319.

9. Mitchell JA, Reddy JN. A refined hybrid plate theory for composite laminates with piezoelectric laminae. International Journal of Solids and Structures 1995; 32:2345-2367.

10. Fukunaga H, Hu N, Ren GX. FEM modeling of adaptive composite structures using a reduced higher-order plate theory via penalty functions. International Journal of Solids and Structures 2001; 38:8735-8752.

11. Xu K, Noor AK, Tang YY. Three-dimensional solutions for coupled thermoelectroelastic response of multilayered plates. Computer Methods in Applied Mechanics and Engineering 1995; 126:355-371.

12. Ray MC, Rao KM, Samanta B. Exact solution for static analysis of an intelligent structure under cylindrical bending. Computers and Structures 1993; 47:1031-1042.

13. Dube GP, Upadhyay MM, Dumir PC, Kumar S. Piezothermoelastic solution for angle-ply laminated plate in cylindrical bending. Structural Engineering and Mechanics 1998; 6:529-542.

14. Vel SS, Batra RC. Cylindrical bending of laminated plates with distributed and segmented piezoelectric actuators/sensors. AIAA Journal 2000; 38:857-867.

15. Fernandes A. Model et Etude de Composants Piezoelectriques: Applications aux Structures Multifonctionnelles. Ph.D. Thesis, L'Universite Paris VI, France, 2000.

16. Raja S, Prathap G, Sinha PK. Active vibration control of composite sandwich beams with piezoelectric extension-bending and shear actuators. Smart Materials and Structures 2002; 11:63-71.

17. Lam KY, Peng XQ, Liu GR, Reddy JN. A finite-element model for piezoelectric composite laminates. Smart Materials and Structures 1997; 6:583-591.

18. Trindade MA, Benjeddou A, Ohayon R. Piezoelectric active vibration control of damped sandwich beams. Journal of Sound and Vibration 2001; 246:653-677.

19. Tzou HS, Tseng CI. Distributed piezoelectric sensor/actuator design for dynamic measurement/control of distributed parameter system: a piezoelectric finite element approach. Journal of Sound and Vibration 1990; 138: $17-34$.

20. Koko IS, Orisamolu IR, Smith MJ, Alepan UO. Alepan, finite element based design tool for smart structures. In Smart Structures and Materials, Varadan VV, Chandra J (eds), vol. 3039. Washington, SPIE. 1997; $125-134$.

21. Park C, Walz C, Chopra I. Bending and torsion models of beams with induced-strain actuators. Smart Materials and Structures 1996; 5:98-113.

22. Spearritt DJ, Asokanthan SF. Torsional vibration control of a flexible beam using laminated PVDF actuators. Journal of Sound and Vibration 1996; 193:941-956.

23. Zhu ML, Lee SWR, Li HL, Zhang TY, Tong P. Modelling of torsional vibration induced by extension-twisting coupling of anisotropic composite laminates with piezoelectric actuators. Smart Materials and Structures 2002; 11:55-62. 
24. Ganapathi M, Patel BP, Polit O, Touratier M. A $\mathrm{C}^{1}$ finite element including transverse shear and torsion warping for rectangular sandwich beams. International Journal for Numerical Methods in Engineering 1999; 45:47-75.

25. Vidoli S, Batra RC. Coupled extensional and torsional deformations of a piezoelectric cylinder. Smart Materials and Structures 2001; 10:300-304.

26. Beakou A, Touratier M. A rectangular finite element for analysing composite multilayered shallow shells in statics, vibration and buckling. International Journal for Numerical Methods in Engineering 1993; 36:627-653.

27. Cheng S, Wei X, Jiang T. Stress distribution and deformation of adhesive-bonded laminated composite beams. Journal of Engineering Mechanics (ASCE) 1989; 115:1150-1162.

28. Jones RM. Mechanics of Composite Materials. McGraw-Hill: New York, 1975.

29. Wetherhold RC, Panthalingal N. Piezoelectric PZT/epoxy composites for controlling torsional motion. Journal of Intelligent Material Systems and Structures 1994; 5:576-580. 